1

2

3

4

5

6

\title{
Pituitary tumors contain a side population with tumor stem cell-associated characteristics
}

Freya Mertens ${ }^{1}$, Lies Gremeaux ${ }^{1}$, Jianghai Chen ${ }^{1,2,+}$, Qiuli Fu ${ }^{1,3}$, Christophe Willems ${ }^{1}$, Heleen Roose ${ }^{1}$, Olivier Govaere ${ }^{4}$, Tania Roskams ${ }^{4}$, Carolina Cristina ${ }^{5}$, Damasia Becú-Villalobos ${ }^{6}$, Mark Jorissen ${ }^{7}$, Vincent Vander Poorten ${ }^{8}$, Marie Bex ${ }^{9}$, Johannes van Loon ${ }^{10}$ and Hugo Vankelecom ${ }^{1,++}$

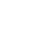

${ }^{1}$ Department of Development and Regeneration, Cluster Stem Cell Biology and Embryology, Research Unit of Stem Cell Research, KU Leuven (University of Leuven), Leuven, Belgium; ${ }^{2}$ Department of Hand Surgery, Tongji Medical College, Union Hospital, Huazhong University of Science \& Technology (HUST), Wuhan, Hubei, China; ${ }^{3}$ Eye Center, Second Affiliated Hospital, School of Medicine, Zhejiang University, Hangzhou, and Key Laboratory of Ophthalmology of Zhejiang Province, China; ${ }^{4}$ Department of Imaging and Pathology, KU Leuven; ${ }^{5}$ CITNOBA (National Research Council of Argentina), National University of the Northwest of Buenos Aires (CONICET-UNNOBA), Pergamino, Buenos Aires, Argentina; ${ }^{6}$ Lab. of Pituitary Regulation, Instituto de Biologia y Medicina Experimental, CONICET, Buenos Aires, Argentina; ${ }^{7}$ Unit Head and Neck Oncology, ${ }^{8}$ Research Group Experimental Oto-rhino-laryngology, ${ }^{9}$ Unit Clinical and Experimental Endocrinology, and ${ }^{10}$ Research Group Experimental Neurosurgery and Neuroanatomy, University Hospitals Leuven, Leuven, Belgium.

${ }^{++}$Corresponding author: Hugo Vankelecom, Department of Development and Regeneration, Cluster Stem Cell Biology and Embryology, Research Unit of Stem Cell Research, KU Leuven, Campus Gasthuisberg O\&N4, Herestraat 49, B-3000 Leuven, Belgium. Fax: +32-16-330642. Phone: +32-16330692. Email address: Hugo.Vankelecom@med.kuleuven.be. ${ }^{+}$Co-corresponding author: Jianghai Chen, Department of Hand Surgery, Tongji Medical College, Union Hospital, Huazhong University of Science \& Technology (HUST), Jiefang Avenue 1277\#, ?Wuhan, Hubei 430022,?]P.R. China. Phone: +86278535 1628. Email address: chenjianghai@hust.edu.cn.

Keywords: pituitary, adenoma, side population, epithelial-mesenchymal transition, tumor stem cells, cancer stem cells, stem cells, Sox2, Cxcr4. 


\section{Abstract}

Pituitary adenomas cause significant endocrine and mass-related morbidity. Only little is known about mechanisms underlying pituitary tumor pathogenesis. We searched for a side population (SP) in pituitary tumor, representing cells with high efflux capacity and potentially enriching for tumor stem cells (TSC). Human pituitary adenomas contain a SP irrespective of hormonal phenotype. This adenoma SP, as well as the purified SP (pSP) depleted from endothelial and immune cells, enriches for cells that express 'tumor stemness' markers and signaling pathways, including epithelialmesenchymal transition (EMT)-linked factors. Pituitary adenomas were found to contain selfrenewing sphere-forming cells, considered a property of TSC. These sphere-initiating cells were recovered in the PSP. Because benign pituitary adenomas do not grow in vitro and failed to expand in immunodeficient mice, the pituitary tumor cell line AtT20 was further used. We identified a SP in this cell line and found it more tumorigenic than the non-SP 'main population'. Of the two EMTregulatory pathways tested, inhibition of C-X-C chemokine receptor type 4 (Cxcr4) signaling reduced EMT-associated cell motility in vitro as well as xenograft tumor growth, whereas activation of TGF $\beta$ had no effect. The adenoma pSP also showed upregulated expression of the pituitary stem cell marker SOX2. Pituitaries from dopamine receptor D2 knockout $\left(\mathrm{Drd}^{--}\right)$mice bearing prolactinomas, contain more pSP, Sox $2^{+}$and colony-forming cells than wildtype glands. In conclusion, we detected a SP in pituitary tumor and identified TSC-associated characteristics. Our study adds new elements to the unravelment of pituitary tumor pathogenesis and may lead to new therapeutic targets. 


\section{INTRODUCTION}

Pituitary tumors are generally considered as benign adenomas. Radiology and autopsy, often performed for other-than-pituitary-related medical reasons, show a high prevalence of $10-15 \%$ in the overall population although most of these lesions are small and asymptomatic (Daly et al. 2009; Melmed 2011). Clinically relevant pituitary adenomas have a lower prevalence of $\sim 0.1 \%$ (Daly et al. 2009), but still represent the third most frequent intracranial neoplasm after meningiomas and gliomas. Tumorigenesis in the pituitary can pose serious medical complications. Tumors may hypersecrete one or more of the pituitary hormones, leading to severe endocrine disturbances and pernicious impact on the many physiological processes governed by the gland. Growth hormone (GH)-producing adenomas (somatotropinomas, GH-A) cause gigantism or acromegaly, ACTHproducing tumors (corticotropinomas, ACTH-A) lead to Cushing's disease and prolactin (PRL)producing adenomas (prolactinomas, PRL-A) negatively affect gonadal status and reproduction. Conversely, a large number of pituitary tumors do not measurably secrete hormones (i.e. nonfunctioning adenomas, NF-A), but their growth and expansion may lead to deficient function of the gland (hypopituitarism) and visual disturbances due to compression of the optic chiasm and nerves. In general, $30-45 \%$ of the clinically diagnosed adenomas display this local expansion as well as invasion of neighboring structures such as the bony sphenoid sinus and the parasellar venous cavernous sinuses (Galland et al. 2010). Current therapeutic approaches that include transsphenoidal resection, pharmacotherapy and irradiation remain inadequate in a significant number of patients (Daly et al. 2009; Galland et al. 2010). The degree of invasiveness appears a critical determinant for the success rate of surgical removal and thus for relapse. At present, mechanisms underlying the pathogenic processes of initiation, expansion, invasion and/or relapse of pituitary tumors are largely uncomprehended. Only a minority $(\sim 5 \%)$ of the tumors are hereditary and traced back to genetic mutations, existing either as isolated tumors or as a component of a larger endocrine syndrome like Men-1 (Daly et al. 2009; Melmed 2011). 
In other types of tumors, so-called cancer stem cells (CSC) have been identified, a pool of

relatively undifferentiated transformed cells that self-renew and propagate the entire range of tumor cell progeny. Compared to the other cells in the tumor, the CSC subpopulation is considered more tumorigenic and more resistant to therapy, thereby surviving treatment and finally re-growing the (heterogeneous) tumor (Vankelecom \& Gremeaux 2010; Clevers 2011; Vankelecom 2012; Vankelecom \& Chen 2014). Recently, CSC have been reported to display characteristics of epithelialmesenchymal transition (EMT) which may drive these cells in tumor expansion and invasive activity (Mani et al. 2008; Morel et al. 2008; Kong et al. 2010; Pirozzi et al. 2011; Yoon et al. 2012). EMT represents a multi-step cell-conversion process during which epithelial cells gradually acquire mesenchymal features. Cells change morphology, lose polarity and cell-cell contacts (e.g. by loss of Ecadherin), become mobile with enhanced invasive capacity, and acquire increased resistance to apoptosis. More in general, EMT is known to play a key role in cancer pathogenesis, particularly during growth, maintenance (including resistance to hostile conditions) and progression of the tumor with local invasion and/or metastasis (De Craene \& Berx 2013). In several types of cancer, it was discovered that EMT markers are enriched in the CSC fraction, that induction of EMT causes upregulated expression of 'stemness' genes, and that EMT acts as a key driver in the generation and activity of the CSC (Mani et al. 2008; Morel et al. 2008; Kong et al. 2010; Pirozzi et al. 2011; Yoon et al. 2012).

Although presence and functional (or clinical) relevance of CSC is increasingly documented in a variety of cancers (Clevers 2011; Eppert et al. 2011; Chen et al. 2012; Schepers et al. 2012; Boumahdi et al. 2014; Vanner et al. 2014; Zhu et al. 2014), the concept remains debated and is likely not applicable to all types of cancer. Nonetheless, the model may help to understand pathogenesis, therapy resistance and recurrence of tumors. At present, CSC have mostly been identified in malignant types of cancer. Whether benign tumors also contain CSC (then better referred to as tumor stem cells or TSC) has only limitedly been studied (Vankelecom \& Gremeaux 2010; Lapouge et al. 2011; Boumahdi et al. 2014). The search for CSC is generally performed on the basis of 'stemness'- 
associated membrane markers or of functional traits. High efflux capacity, mediated by ATP-binding cassette $(A B C)$ multidrug transporters, is considered one functional property of CSC, rendering the cells more resistant to chemotherapeutic drugs. In the present study, we searched for cells possessing such efflux capacity using the 'side population' (SP) technique (Chen et al. 2005, 2009). Cells extruding Hoechst dye are observed as a side branch of Hoechst ${ }^{\text {low }}$ cells in dual-wavelength FACS analysis. In a variety of cancer types, a SP has been identified and found enriched in CSC or CSClike cells (Patrawala et al. 2005; Wu \& Alman 2008; Kato et al. 2010; Britton et al. 2012; Moti et al. 2014). Thus, we searched for SP cells in human pituitary adenomas and in additional models of pituitary tumor (mouse tumor, cell line, xenograft tumors). We identified a SP and observed molecular and functional characteristics supportive of a TSC-associated phenotype. In addition, we identified the Cxcr4 pathway as an interesting target for further investigation in pituitary tumor treatment. 


\section{MATERIALS AND METHODS}

\section{Pituitary adenomas}

Human pituitary adenoma samples were obtained immediately after transsphenoidal resection at the University Hospitals Leuven (Division Neurosurgery). Informed consent was received from the patients. Hormonal phenotype was determined by the Department of Imaging and Pathology (University Hospitals Leuven). An overview of the samples with clinical data is provided in Table 1. Genders are represented equally with an average age of $53 \mathrm{yr}$ (range: 19-84 yr) at the time of surgery. The majority of the tumors are NF-A $(n=34)$ and GH-A $(n=21)$. Other types of resected pituitary tumors typically are microadenomas only yielding sufficient study material in a limited number of cases (ACTH-A; $n=3)$, or are not surgically removed but treated pharmacologically (resected PRL-A; $n=2)$.

Tumor samples were either immediately processed for flow-cytometric analysis after resection, or cryopreserved as small pieces in Leibovitz-L-15 medium (Life Technologies, Carlsbad, CA) supplemented with $10 \%$ fetal bovine serum (FBS; Lonza, Rockland, ME) and 10\% dimethylsulfoxide (DMSO; Sigma-Aldrich, Bornem, Belgium) followed by storage at $-196^{\circ} \mathrm{C}$ for later examination. The freezing procedure did not change the SP proportion (see Supplementary Fig. S1) or the expression characteristics as evident from the microarray analyses.

\section{Dissociation of human pituitary adenoma into single cells}

Tumor samples were rinsed in Dulbecco's Modified Eagle's Medium (DMEM; Life Technologies) supplemented with $0.3 \%$ bovine serum albumin (BSA; Serva, Heidelberg, Germany) and incubated with collagenase type IV (1 $\mathrm{mg} / \mathrm{ml}$ in Medium 199; Life Technologies) for 2-2.5 hr at $37^{\circ} \mathrm{C}$. Cell debris was removed by centrifugation through a 3\% BSA layer. The resultant cell pellet was resuspended in pituitary-optimized, serum-free chemically defined medium (SFDM, Life Technologies; supplemented with 0.5\% BSA; Chen et al. 2005, 2009) for further analyses. 
Immunohistology of human pituitary adenoma sections

Formalin-fixed paraffin-embedded pituitary adenoma blocks were obtained from the Biobank (University Hospitals Leuven). Antigen retrieval was performed on 5- $\mu$ m sections using EnVision FLEX Target Retrieval Solution (Dako, Glostrup, Denmark). Endogenous peroxidase activity was blocked using EnVision Peroxidase-Blocking Reagent and sections were incubated with primary antibodies directed against human E-cadherin (Ready-to-use; Dako), vimentin (1/500; Dako), NOTCH2 (1/200; Abcam, Cambridge, UK) and IL-6 (1/200; Abcam). Subsequently, samples were processed using EnVision Dual Link (Dako). The complex formed was visualized with 3,3'-diaminobenzidine (DAB; Dako) and sections were counterstained with hematoxylin (Dako).

\section{Isolation and dissociation of mouse pituitary}

C57/BI6 mice were purchased from Elevage Janvier (BioServices, Uden, The Netherlands), and dopamine D2 receptor knockout ( $\mathrm{Drd}^{-/}$) mice from The Jackson Laboratory (Bar Harbor, ME). Mice were kept or bred in the KU Leuven Animal Facility under conditions of constant temperature, humidity and day-night cycle in a sterile environment. Food and water were supplied ad libitum. Animal experiments were approved by the KU Leuven Ethical Committee.

The pituitary was isolated from euthanized mice as previously described (Chen et al. 2005, 2009). The anterior lobe (anterior pituitary, AP) of the $\operatorname{Drd}^{-\%}$ mice growing prolactinomas (from 6 to 14 months of age; Cristina et al. 2006), and of the respective control mice $\left(\operatorname{Drd2^{+/-}}\right.$ and $\left.D r d 2^{+/+}\right)$was dispersed into single cells using collagenase type IV as explained above for human pituitary adenomas.

\section{Culture and treatment of AtT20}

The mouse corticotrope AtT20 cell line was obtained from American Type Culture Collection (ATCC, CCL-89; Manassas, VA). The cell line was authenticated by hormone expression analysis with RT-quantitative (q)PCR (see below). The cells were cultured in DMEM/F12 (Life Technologies) 
supplemented with $10 \%$ FBS. To investigate involvement of the transforming growth factor- $\beta$ (TGF $\beta$ ) or Cxcr4 pathways, AtT20 cells were cultured in serum-free medium for $18-24 \mathrm{hr}$ and then treated with TGF $\beta 1$ (5ng/ml; R\&D Systems, Minneapolis, MN) or AMD3100 (octahydrochloride, 100ng/ml; Sigma-Aldrich), respectively. Medium was refreshed every $24 \mathrm{hr}$. To analyze gene expression and SP proportion after treatment (see below), cells were detached and dissociated using trypsin $(0.05 \%)$ with EDTA (0.02\%; Life Technologies).

\section{Flow cytometry}

Dissociated cells (from human adenoma or mouse AP, AtT20 cell line or xenograft tumors - see below) were processed for SP analysis as described in detail before (Chen et al. 2005, 2009). In short, cells were incubated with the vital dye Hoechst33342 (Sigma-Aldrich) at a final concentration of $2.5 \mu \mathrm{g} / \mathrm{ml}$ (for mouse AP and AtT20) or $5 \mu \mathrm{g} / \mathrm{ml}$ (for adenoma and xenograft samples). Subsequently, cells were either immediately analyzed by FACS (Vantage or Aria III; BD Biosciences) or first stained with phycoerythrin (PE)-conjugated mouse anti-human CD45, FITC-conjugated mouse anti-human CD31, PE-conjugated mouse anti-mouse CD45 and/or FITC-conjugated rat anti-mouse CD31 antibodies, using dilutions recommended by the manufacturer (BD Biosciences). Samples were examined for SP on the basis of dual-wavelength emission using appropriate filters (Vantage: 424/44 and 630/22; Aria III: 450/40 and 630/20) after (near-)UV excitation (360 and 375nm on Vantage and Aria III, respectively). The SP phenotype was verified by adding verapamil (100 $\mathrm{MM}$; Sigma-Aldrich) which blocks the Hoechst efflux. The bulk cell population not expelling Hoechst is designated as the 'main population' (MP). CD31 and CD45 staining was controlled using isotype antibodies (BD Biosciences; data not shown).

\section{Xenograft tumors and in vivo tumorigenic activity}

In an attempt to grow human pituitary adenoma in immunodeficient mice, tumor pieces or dissociated cells $\left(1-1.5 \times 10^{6}\right)$ were transplanted subcutaneously (sc) (GH-A and NF-A, $\left.n=8\right)$ or under 
the kidney capsule (GH-A and ACTH-A, n=3). Male mice (6-10 weeks old) with increasing grade of immunodeficiency (from SCID, NOD-SCID to NOD-SCID ${ }^{\mathrm{IL2RY}-/}$ ) were purchased from Elevage Janvier, and were anesthetized with Avertin (tribromoethanol; Sigma-Aldrich). Prior to injection, cells were resuspended in DMEM mixed with Matrigel (1:1; BD Biosciences). Three to six months later, mice were examined for tumor growth after euthanasia. Tissue of implantation sites was dissected and hematoxylin/eosin (H\&E) staining performed.

To grow xenograft tumors from AtT20 cells, SCID mice (male; 6-10 weeks old) were sc injected with $5 \times 10^{5}$ cells. To assess tumorigenic (TSC) activity of the AtT20 SP versus the MP, cell populations were sorted into DMEM/F12/10\% FBS, mixed with Matrigel (1:1), and sc injected at different cell numbers into SCID mice (SP cells in one flank, the similar number of MP cells in the other flank of the same mouse). Tumor size was measured using a caliper and volume calculated with the formula '[(large side) $\left.\times(\text { small side })^{2}\right] \times 0.52$ '.

To explore the involvement of the Cxcr4 pathway, AtT20 xenograft tumors developing in SCID mice were treated with AMD3100 by intratumoral injection ( $5 \mu \mathrm{g}$, two times/week), starting from day 21 after sc AtT20 cell implantation.

\section{Tumorsphere- and colony-forming assay}

Dissociated human pituitary adenoma cells were seeded at a density of 100000 cells $/ \mathrm{ml}$ in 35mm non-treated culture dishes (Iwaki, Scitech, Chiba, Japan) and cultured in SFDM, supplemented with B27 (1:50; Life Technologies) and recombinant basic fibroblast growth factor (bFGF, 20ng/ml; R\&D Systems). Fresh medium was added every 3 days. To assess self-renewal capacity, spheres were harvested, dissociated into single cells using trypsin (Chen et al. 2009) and cells re-seeded under similar conditions.

To evaluate colony-forming capacity, cells were cultured at low density (1000-4000 cells/60-mm dish) in Ultraculture medium (Life Technologies) to which $5 \% \mathrm{FBS}, 20 \mathrm{ng} / \mathrm{ml} \mathrm{bFGF}$ and $50 \mathrm{ng} / \mathrm{ml}$ cholera toxin (Sigma-Aldrich) were added. Medium was changed every 3 days. Cultures were fixed 
with methanol and stained with 1,9-dimethyl-methylene blue (Sigma-Aldrich), and the number of colonies was determined. Live pictures of the formed spheres and colonies were taken using a Nikon Eclipse TS100 microscope (Nikon Instruments, Melville, NY).

\section{Cell motility assay}

Cell motility was evaluated using the 'scratch assay'. After reaching $90 \%$ of confluence, AtT20 cells were serum-starved for $24 \mathrm{hr}$ and then treated with mitomycin C $(10 \mu \mathrm{g} / \mathrm{ml}$; Kyowa, Tokyo, Japan) to inhibit cell proliferation. A straight scratch was created and cells were further kept in DMEM/F12, together with TGFß1 (5ng/ml), AMD3100 (100ng/ml) or vehicle. Medium was changed every $24 \mathrm{hr}$. Migration of cells into the scratch was evaluated by light microscopy and live pictures were taken with the Nikon Eclipse TS100 microscope at different time points. The open area was calculated using analysis algorithm-based T-scratch software (CSElab-ETH, Zürich, Switzerland).

\section{Small-animal magnetic resonance imaging}

Magnetic resonance imaging (MRI) was performed on $\mathrm{Drd}^{--}$and $\mathrm{Drd2}^{+-}$mice using a horizontal 9.4-Tesla nuclear magnetic resonance spectrometer and a 40-mm-diameter birdcage coil as radio frequency transmitter and receiver. Mice were anesthetized using $1 \%$ isoflurane in a mixture of $75 \%$ air and $25 \%$ oxygen. T1-weighted images were acquired using a two-dimensional multiple-slice spin echo sequence, with an echo time of $11 \mathrm{msec}$, a repetition time of $500 \mathrm{msec}$, in-plane resolution of $0.1 \times 0.1 \mathrm{~mm}, 24$ coronal slices with $0.3-\mathrm{mm}$ slice thickness, and 10 signal averages. Image reconstruction was performed using the spectrometer console. Ten minutes prior to the scanning procedure, mice received an intraperitoneal injection of the contrast agent gadolinium $(0.50 \mathrm{mmol} / \mathrm{kg}$ body weight). 
Immunofluorescence analysis

For immunofluorescence examination of mouse pituitaries, whole glands were isolated and fixed with paraformaldehyde (4\%; Riedel-de Haën, Seelze, Germany). After agarose embedding, pituitaries were coronally sectioned to $45-\mu \mathrm{m}$ slices using a vibratome (Microm HM 650V; Prosan, Merelbeke, Belgium). Sections were permeabilized with $0.4 \%$ Triton-X 100 (Sigma-Aldrich) and incubated overnight with the following primary antibodies: goat anti-human SOX2 (1/750; Immune Systems, Devon, UK) and rabbit anti-mouse prolactin (PRL) (1/10 000; from Dr. A.F Parlow, NHPP, Harbor-UCLA Medical Center, Torrance, CA). Finally, sections were incubated with AlexaFluor 488conjugated donkey anti-rabbit and/or AlexaFluor 555-conjugated donkey anti-goat antibodies (1/1000; Life Technologies), and nuclei labeled with ToPro3 (Life Technologies). Immunofluorescence was examined using a Zeiss LSM 510 confocal laser-scanning microscope (Zeiss, Zaventem, Belgium) accessible through the Cell Imaging Core (CIC; KU Leuven). Z-stacks were collected and analyzed using Zeiss LSM Image Browser and ImageJ (http://imagej.nih.gov/ij/), and pictures were prepared using the same programs and Microsoft PowerPoint (2007).

Immunofluorescence staining of paraffin-embedded mouse pituitary sections $(5 \mu \mathrm{m})$ was performed after antigen retrieval with citrate buffer $(\mathrm{pH} \mathrm{6)}$ and permeabilization with Triton-X 100 (0.1\% in PBS). Following incubation with primary and secondary antibodies (as above), sections were covered with Vectashield (containing 4',6-diamidino-2-phenylindole or DAPI) and analyzed using a Leica DM5500 epifluorescence microscope (Leica Microsystems, Diegem, Belgium) accessible through InfraMouse (KU Leuven-VIB). Recorded images were converted to pictures with ImageJ and Microsoft PowerPoint (2007).

Cytospin samples of dissociated mouse AP cells were fixed with paraformaldehyde (4\%), permeabilized with saponin (0.5\%; Sigma-Aldrich), and further immunostained for Sox2 (with goat anti-human SOX2 at 1/250; Immune Systems) as described above. In some analyses, cells were at the same time immunostained for the proliferation marker Ki67 (with rabbit anti-Ki67 at 1/50; Thermo Scientific, Fremonet, CA). Nuclei were counterstained with DAPI $(0.5 \mu \mathrm{g} / \mathrm{ml})$. To enumerate Sox2- 
immunopositive cells, pictures were captured using the Leica DM5500 microscope, and cells counted with ImageJ in 5 to 10 random fields per group in each experiment (about 1500 cells per group in each experiment). The proportions of the Sox $2^{+}$cells (on total cells counted) were determined. Because of the increase of total AP cells in the $\operatorname{Drd} 2^{-/}$adenomatous pituitary, comparison of proportions is not appropriate. Thus, absolute numbers of Sox $2^{+}$cells were calculated (using their proportion and the total number of AP cells obtained per experimental group of mice) for comparison between $\operatorname{Drd}^{-/}, \operatorname{Drd}^{+/-}$and $\operatorname{Drd}^{+/+}$mice.

For immunofluorescence examination of tumorspheres developed from human pituitary adenomas, fixation with paraformaldehyde (4\%) and permeabilisation with Triton-X100 (0.4\% in PBS) were followed by incubation with goat anti-human SOX2 (1/250; Immune Systems), rat anti-mouse nestin (1/500; Abcam) and/or rabbit anti-human GH (for spheres originating from GH-A; 1/2000; Dako). Secondary antibodies included AlexaFluor 555-conjugated donkey anti-goat, AlexaFluor 488conjugated donkey anti-rat, and AlexaFluor 488-conjugated donkey anti-rabbit (all at 1/1000; Life Technologies). Pictures were obtained with the Leica DM5500 epifluorescence microscope as described above.

\section{AtT20 cell death, apoptosis and proliferation}

The number of dying or dead AtT20 cells after AMD3100 treatment $(100 \mathrm{ng} / \mathrm{ml})$ was determined after staining with Trypan Blue (0.4\%; Sigma-Aldrich). Apoptosis was scored by TUNEL (Terminal deoxynucleotidyl transferase dUTP nick end labeling) analysis in cytospin samples of AtT20 cells from culture or xenograft tumors, using the FragEL kit (Calbiochem, Darmstadt, Germany). Cell proliferation was quantified by immunofluorescence staining of cytospin samples for Ki67 as described above. Pictures were taken and cells enumerated (see above). 
Whole-genome expression profiling

Total SP and MP cells (NF-A, $n=5 ; \mathrm{GH}-\mathrm{A}, \mathrm{n}=4$ ) or $\mathrm{CD}^{-} 1^{-} / \mathrm{CD}^{-} 5^{-} \mathrm{SP}$ (purified SP or pSP) and $\mathrm{pMP}$ cells (NF-A, $n=5$ ) were sorted by FACS into cold lysis solution of the RNeasy Micro Kit (Qiagen, Venlo, The Netherlands). Total RNA was extracted immediately after cell collection according to the manufacturer's guidelines. RNA samples were stored at $-80^{\circ} \mathrm{C}$ until further processing for wholegenome expression profiling (in collaboration with the VIB Nucleomics Core, KU Leuven). RNA quality and concentration were determined using Agilent Picochips on an Agilent BioAnalyzer 2100 (Agilent Technologies, Santa Clara, CA). Two ng of high-quality RNA (with RNA Integrity Number $\geq 8.0$ ) was amplified using the NuGen Pico WTA kit (NuGen Technologies, San Carlos, CA). Cy3 label was incorporated into the cRNA probes which were then hybridized onto Agilent whole human genome $44 \mathrm{~K}$ oligonucleotide arrays. Slides were scanned and data processed using the Agilent's Feature Extraction Software for background correction, quantile normalization, Principal Component Analysis (PCA), hierarchical clustering, and MA and Volcano plots. Microarray data are available from the NCBI's Gene Expression Omnibus (GEO, http://www.ncbi.nlm.nih.gov/projects/geo/) through series accession number GSE62960.

To determine differentially expressed genes (probes), a stringent analysis was initially applied to the normalized data sets. Taken into account that the data are paired (SP versus MP for each sample), analysis was based on the $\log _{2}$-ratios computed for each pair. $\log _{2}$-ratios were compared with the Limma (Linear Models for Microarray Data) package of Bioconductor in R and a moderated t-statistic (implemented in Limma) was performed to test the significance of the obtained differences. For the first microarray data set (total SP versus MP), the resulting $p$-values were corrected for multiple testing with Benjamini-Hochberg to control the false discovery rate. Differentially expressed genes were withheld when the corrected $p$-value was lower than 0.05 . For the second microarray data set $\left(\mathrm{CD} 31^{-} / \mathrm{CD}^{-} 5^{-} \mathrm{SP}\right.$ versus $\left.\mathrm{CD} 31^{-} / \mathrm{CD} 45^{-} \mathrm{MP}\right)$, Benjamin-Hochberg could not be applied because of the low number of samples. Therefore, a cut-off based on the uncorrected $p$-values $(p<0.001)$ was utilized. For both data sets, the cut-off on the $p$-values was 
combined with a cut-off on the fold change $(\geq 2)$ to finally determine the differentially expressed genes.

Given the not yet large number of adenomas analyzed, causing a very high cut-off for differential expression and hence the discard of potentially interesting differences, we additionally applied a less stringent analysis by paired Students t-test performed on the individual probe sets. Genes were judged differentially expressed when $p<0.05$ and fold change $\geq 1.5$. We further considered genes that showed a significant expression difference in not all but in 5 to 8 out of the 9 adenomas analyzed for total SP and MP, and in 2 to 4 out of the 5 adenomas examined for $\mathrm{CD} 31^{-} / \mathrm{CD} 45^{-}$fractions.

Functional clustering analysis of differentially expressed genes (Gene Ontology, GO) was performed using the Database for Annotation, Visualization and Integrated Discovery (DAVID, version 6.7; www.david.abcc.ncifcrf.gov). Gene clusters with enrichment score $>1.5$ (-log of the median $p$-value for the functional group) were retained. Finally, we narrowed the gene sets by focusing on factors shown to be important in CSC/'tumor stemness' including EMT, NOTCH, WNT/ $\beta$ CATENIN and TGFß/BMP.

\section{Gene expression analysis by RT-qPCR}

Amplified cDNA of the $\mathrm{CD} 31^{-} / \mathrm{CD}^{-} 5^{-} \mathrm{SP}$ and MP fractions from the 5 microarrayed NF-A samples, as well as from 2 additional samples (NF-A, $n=1 ; G H-A, n=1$; see Table 1), was examined by RT-qPCR to validate expression of a selection of genes using Fast SYBR Green Master Mix on an ABI 7900HT Fast RT-PCR system, performed according to the manufacturer's instructions (Life Technologies).

Gene expression analysis of AtT20 cells or dispersed xenograft tumors occurred using a similar approach (but without the RNA amplification step). cDNA was subjected to qPCR in a LightCycler 480 using the LightCycler FastStart DNA Master Plus SYBR Green I (Roche, Basel, Switzerland).

$\begin{array}{cccccc}\text { Forward and reverse } & \text { primers were } & \text { designed using } & \text { PerLPrimer } \\ & & \text { or obtained from a public } & \text { database }\end{array}$


346 (http://medgen.ugent.be/rtprimerdb), and are described in Supplementary Table S1. 347 Glyceraldehyde-3-phosphate dehydrogenase (GAPDH), $\beta 2$-microglobulin (B2M) and/or hypoxanthine 348 phosphoribosyltransferase 1 (HPRT1) were used to normalize gene expression. Their expression was 349 found to be stable (data not shown). Relative gene expression levels were calculated as $\Delta \mathrm{Ct}$ values 350 ('Ct target minus Ct reference') and compared between the SP and MP as fold change 351 (2- $\left.{ }^{-\Delta C t} \mathrm{SP} / 2^{-\Delta C t} \mathrm{MP}\right)$. Statistical analysis was performed using Graphpad Prism (Version 5.2; Graphpad 352 Software, La Jolla, CA) applying the Mann-Whitney $U$ test. P-values $<0.05$ were considered as 353 statistically significant.

354 For authentication of the AtT20 cell line used, hormone gene expression was examined by RT355 qPCR. The corticotrope phenotype of the cell line was confirmed by detection of pro356 opiomelanocortin (POMC; precursor of ACTH) expression, while $\mathrm{GH}$ and thyroid-stimulating 357 hormone- $\beta($ TSH $\beta$ ) gene transcription was not found (see Supplementary Table S2). 


\section{RESULtS}

\section{Human pituitary tumors contain a side population}

Human pituitary adenomas ( $n=60$; see Table 1 ) were examined for the presence of a SP. In all tumors analyzed, a Hoechst ${ }^{\text {low }}$ cell population was detected which was not observed anymore when the efflux-blocker verapamil was added together with Hoechst (Fig. 1A), thereby demonstrating the SP phenotype (mean SP \pm SEM: $1.9 \% \pm 0.3$ of the total viable tumor cells; range: $0.4-17.2 \%$; Table 1 ) SP proportions were not different between the samples analyzed immediately after surgical resection $(n=24)$ or after cryopreservation $(n=36)$ (Table 1; Supplementary Fig. S1A), neither between the different hormonal phenotypes examined (Fig. 1B; Table 1). The adenoma SP predominantly clusters cells of small to medium size (low 'forward scatter') and low granularity (low 'side scatter') (Supplementary Fig. S1B).

\section{Whole-genome expression profiling of the adenoma SP points to epithelial-mesenchymal} transition and 'tumor stemness'

SP cells and the tumor bulk MP cells from somatotropinomas (GH-A, n=4) and non-functioning adenomas (NF-A, $n=5$; see Table 1) were sorted by FACS and subjected to gene expression profiling using whole-genome microarrays. Principal component analysis (PCA) indicates a comparable segregation of the SPs from the corresponding MPs for the majority of the samples analyzed (Supplementary Fig. S1C). Hierarchical clustering of differentially expressed genes also largely separates the SPs from the MPs (Supplementary Fig. S1D).

The set of genes most differentially expressed $(p<0.001 ; 2760$ probe sets) was submitted to DAVID for Gene Ontology (GO) analysis, yielding a total of 1688 corresponding human ENSEMBL IDs. Gene set enrichment exposes in the SP upregulation of biological functions involved in cell proliferation, vascular development, cell migration and motility, and lymphocyte activation (Supplementary Table S3). 
A focused analysis of a selection of genes using the expression data of the 9 adenomas (Table 2 and Supplementary Table S4) reveals upregulated expression (i.e. $>1.5$-fold in at least $2 / 3^{\text {rd }}$, or in 5 of the 9 tumors, $\mathrm{p}<0.05$; see Materials and Methods) in the SP of the multidrug transporters $A B C B 1$ and $A B C G 2$ that typically underlie the SP phenotype, thereby validating the SP identification and sorting procedure. Remarkably, the transcriptome displays an expression pattern that supports occurrence of EMT in the SP compartment. The epithelial markers E-cadherin (CDH1) and claudin-1 (CLDN1) are downregulated in the pituitary adenoma SP whereas the mesenchymal markers vimentin (VIM) and fibronectin (FN1) are upregulated (Table 2 and Supplementary Table S4). Moreover, recognized markers of EMT such as SNAI1, ZEB1 and ZEB2 (all transcriptional repressors of the CDH1 gene) are higher expressed in the SP versus the MP together with other inductors and regulators of EMT (KLF8, LEF1, TCF4, FOXC1, HOXB9, FOSL2, MMP1/2 and CXCR4). Some of the pathways identified as upregulated are also well known for their regulatory input in EMT (WNT, TGF $\beta$, epiregulin or ERG, amphiregulin or AREG). In this analysis, we also observed that factors often associated with 'tumor stemness' or CSC, including CD44, CXCR4, KIT, KLF4 and NESTIN are upregulated in the SP. In addition, the signaling pathways of NOTCH, WNT and TGF $\beta$ ? BMP have also been related to 'tumor stemness'. Overall, no obvious differences were observed between the SP transcriptomes of the NFA and the GH-A samples.

Of note, the microarray analysis also revealed upregulated expression of genes associated with an endothelial phenotype (such as PECAM1/CD31, VWF, CDH5, VCAM1, FLK1/KDR, TIE1, TEK/TIE2) or an immune character (such as CD45/PTPRC) in the adenoma SP (see Table 2 and Supplementary Table S4). These expression characteristics are in line with the enriched biological processes as described above (viz. vascular development and lymphocyte activation; see Supplementary Table S3) and suggest the presence of endothelial and immune/hematopoietic cells in the SP. Before, we and others have discovered that the SP, whether from healthy tissue or tumors, represents a still heterogeneous population, not only segregating cells with (tumor) stem cell properties but also some 
other cells of endothelial and immune/hematopoietic phenotype (Chen et al. 2009; Pfister et al. 2005; Uezumi et al. 2006).

Taken together, our microarray expression data indicate that, compared with the MP, the pituitary adenoma SP is enriched in cells with EMT- and 'tumor stemness'-associated molecular traits, but is still heterogeneous in cell phenotypes.

EMT- and 'tumor stemness'-related expression characteristics remain present in the adenoma SP depleted from endothelial and immune cells

The pituitary adenoma SP was then analyzed for the presence of endothelial $\left(C D 31^{+}\right)$and immune/hematopoietic $\left(C D 45^{+}\right)$cells. Flow cytometry revealed a $\mathrm{CD}^{+} 1^{+}$cell population of varying abundance in the SP (mean \pm SEM: $50.9 \pm 4.8 \%$ of the SP; range: $5.8-95.2 \% ; n=37$; Fig. 1C-D and Table 1). Also $\mathrm{CD} 5^{+}$cells are found but in general constitute a lower fraction of the adenoma SP (16.2 $\pm 3.0 \%$ of the SP; range: $0.2-66.6 \% ; n=31 ;$ Fig. 1 C-D and Table 1). The non-endothelial, nonimmune $\left(\mathrm{CD} 1^{-} / \mathrm{CD} 5^{-}\right) \mathrm{SP}$ fraction finally comprises on average $1 / 3^{\text {rd }}$ of the total $\mathrm{SP}(32.3 \% \pm 2.2$; range: $7.2-64.1 \%), 0.5 \%( \pm 0.1)$ of all $\mathrm{CD}^{-} 1^{-} / \mathrm{CD} 5^{-}$adenoma cells and $0.1 \%( \pm 0.01)$ of the total tumor cell population. In general, no correlation was found between the size of the total SP and the proportion of $\mathrm{CD} 31^{+}$or $\mathrm{CD}_{4} 5^{+}$cells (Table 1 and Fig. 1D), although the 2 samples with the highest SP proportion analyzed for these antigens (PA 26, PA 43) contain the largest fraction of $\mathrm{CD}_{3} 1^{+}$cells in the SP.

To determine whole-genome expression profiles of the non-endothelial, non-immune cell populations, SP and MP were depleted from $\mathrm{CD} 31^{+} / \mathrm{CD} 45^{+}$cells during flow-cytometric sorting (see Fig. 1C for gating; $n=5$ NF-A; Table 1). Stringent analysis revealed 101 genes (probe sets), corresponding to 74 human ENSEMBL IDs in DAVID, which are differentially expressed between the $\mathrm{CD}^{-} 1^{-} / \mathrm{CD}^{-} 5^{-} \mathrm{SP}$ (further referred to as the purified SP or pSP) and the $\mathrm{CD}^{-} 1^{-} / \mathrm{CD} 45^{-} \mathrm{MP}(\mathrm{pMP}), 80$ of which are upregulated in the pSP and 21 downregulated (see Supplementary Fig. S2A-C). The as yet relatively small number of samples analyzed causes a high cut-off for differential expression (as is 
clear from Supplementary Fig. S2A). Therefore, we performed an additional, less stringent examination (see Materials and Methods), analyzing genes not only altered $(\geq 1.5$-fold, $p<0.05$ ) in all adenomas, but also in 4 out of the 5 tumors profiled. A total of 2374 genes (probe sets) were found to be differentially expressed in the pSP compared to the pMP in at least 4 of the adenoma samples (corresponding to 1576 human ENSEMBL IDs), with 1662 and 712 genes up- and downregulated, respectively (Supplementary Table S5). The gene sets obtained in both the stringent and less stringent analyses (101 and 2374 genes, respectively) were submitted to GO examination using DAVID. Overviews of the most significantly enriched biological processes are provided in Supplementary Table S6 and S7, and include, amongst others, cell motility and migration, vascular development, cell proliferation and organ development.

Subsequent analysis of the pSP was focused on a selection of genes as considered above for the total SP, including genes associated with EMT and 'tumor stemness' (Table 3 and Supplementary Table S8). On the whole, the expression picture of the total SP appears retrieved in the $\mathrm{CD}^{-} 1^{-} / \mathrm{CD} 5^{-}$ $\mathrm{SP}$, viz. upregulated expression of $A B C G 2$ and of other CSC-associated markers including $C D 44, C D 34$, LIFR and CXCR4. KIT expression is upregulated in 4 of the 5 samples and NESTIN in 3 of the 5 (Table 3). In particular, the gene expression picture underlying EMT is also present in the pSP, showing elevated expression of the mesenchymal markers VIM and FN1 and of several transcriptional EMT regulators (including SNAI1, SNAI2, ZEB1, ZEB2) (Table 3). Since GO enrichment pointed to gene clusters involved in cell motility and migration, and EMT is known to drive motile and invasive behavior of cells, additional genes involved in these processes were examined. A considerable number were found to be up- or downregulated in the PSP versus the pMP including EPHB1 and TM4SF1 (Supplementary Table S8). Interestingly, also epidermal growth factor receptor (EGFR) is highly (9-fold) upregulated in the pSP (Supplementary Table S8); EGFR has been found to be involved in tumor cell migration in craniopharyngiomas (Hölsken et al. 2011). In addition, several components functioning in NOTCH, WNT and TGF $\beta$ signaling are elevated (Table 3 and Supplementary Table S8). These pathways play a role in EMT and 'tumor stemness' but also in pituitary development (Zhu et al. 
2007; Vankelecom 2010). More in general, gene clusters associated with organ development and differentiation processes are found enriched in the pSP (see Supplementary Tables S4 and S5). Finally, also genes implicated in angiogenesis are upregulated in the pSP versus pMP (Table 3; Supplementary Tables S6, S7 and S8).

Differential expression as concluded from the pSP microarray interrogations was verified by RTqPCR for a number of the most interesting genes (Fig. 1E). For this analysis, the 5 micro-arrayed NF-A samples were complemented with 2 additional tumors (1 NF-A and 1 GH-A; see Table 1). RT-qPCR was found to essentially confirm the microarray data, although statistical significance was not always reached in the as yet relatively limited number of samples analyzed. All 17 genes examined show upregulated expression in the pSP when compared to the pMP (9 with statistical significance, 8 with upward trend; Fig. 1E). Most remarkable are the elevated expression levels of CD44, IL-6, NOTCH2, PDGFRB, SNAI2, VIM and ZEB2, in the pSP over the pMP (>55-fold). A higher expression level (>55fold) was also found for CXCR4, FN1, HES1, PDGFC and TGFBR2, not in all but in at least 5 out of the 7 samples. Expression of $C D H 1$ was also checked but was not significantly different in the pSP versus the pMP, although a trend of downregulation was measured in the pSP of 4 out of the 7 adenomas analyzed. Expression of E-cadherin, vimentin, IL-6 and NOTCH2 was further analyzed by immunohistochemistry in paraffin-embedded sections of pituitary adenomas used above for gene expression analysis ( $\mathrm{n}=6$; see Table 1 and Supplementary Fig. S2D). Tumors with high E-cadherin immunoreactivity contain some zones and cell clusters where E-cadherin is downregulated, and vimentin is expressed in some regions or small nests of tumor cells (in addition to the pericapillar cells), suggesting that some tumor cells may have undergone EMT. IL-6 immunoreactivity was observed in a couple of clustered cells (2-4 per section) in 3 out of the 6 adenomas analyzed, and NOTCH2 immunoreactivity in $1-2$ cells per section in 4 out of the 6 adenomas (Table 1 and Supplementary Fig. S2D). IL-6 and NOTCH2 immunoreactivity were found in the same adenomas, except for PA 34. 
Human pituitary tumors contain sphere-forming cells segregating to the pSP

TSC generate spheres ('tumorspheres') when brought in appropriate suspension-culture conditions (Vankelecom \& Gremeaux 2010; Clevers 2011). When pituitary adenoma cells were cultured in the presence of B27 and bFGF, free-floating spheres developed progressively. After 7 days of culture bright and mostly smooth-edged spheres were obtained which clearly differ from the irregular clumps of aggregated cells that also formed (Fig. 2A-B; $n=13$ encompassing NF-A and GH-A). Sphere cells were found to express the stemness markers Sox2 and nestin (Chen et al. 2009), thereby supporting their TSC character (Fig. 2C and Supplementary Fig. S3A-B; n=3: 1 NF-A and 2 GH-A). At the end of the culture period (day 7-10), some spheres contained cells expressing the hormone produced by the original tumor, suggesting some degree of spontaneous differentiation and further supporting their TSC phenotype (Supplementary Fig. S3C). To examine the self-renewal capacity of the sphere-initiating cells (as a further property of TSC), primary spheres were dissociated and cells seeded again. Secondary spheres with similar morphology developed although fewer in number (Fig. 2D-E; $n=9$ ), likely due to a considerable loss of cells after dispersion of the primary spheres. Thirdgeneration spheres were further also obtained, but were still scarcer (Fig. 2F).

To investigate whether the sphere-forming cells belong to the pituitary tumor's SP, $\mathrm{CD}^{-} 1^{-} / \mathrm{CD}^{-} 5^{-} \mathrm{SP}$ cells were sorted from adenomas and seeded in sphere-forming conditions $(\mathrm{n}=3)$. Spheres developed in the pSP cultures (Fig. 2G) and were absent from pMP cultures that only contained irregular clumps of cells (Fig. 2G, inset). However, only very few spheres could be obtained (2-4 spheres per 20000 pSP cells originally seeded), which made it impossible to get enough viable cells for further passaging after dispersion.

Together, our findings provide supportive evidence that human pituitary adenomas contain selfrenewing sphere-forming cells that give rise to spheres expressing stemness markers, considered as properties of TSC, and further show that the sphere-initiating cells segregate to the pSP.

In addition to the in vitro sphere-forming assay, CSC/TSC activity is typically tested in vivo by (xeno-)transplantation in immunodeficient mice (Vankelecom \& Gremeaux 2010; Clevers 2011; Chen 
et al. 2012; Schepers et al. 2012; Boumahdi et al. 2014). However, we observed that human pituitary adenoma, irrespective of hormonal phenotype, does not grow (i.e. expand) in immunodeficient SCID mice. Although small tumor pieces survived for 3-4 months after sc implantation, no enlargement was detected (data not shown). Xenograft adenoma growth did not only fail in SCID mice but also in the more immunodeficient NOD-SCID and NOD/SCID ${ }^{1 / 2 R \gamma-/-}$ models, after sc implantation of tumor parts as well as of dissociated cells (data not shown). Similarly, pituitary adenoma fragments engrafted under the kidney capsule survived but did not visibly grow in size (as analyzed after 3-6 months; Supplementary Fig. S4). Therefore, to be able to further functionally characterize the pituitary tumor SP and to explore its TSC-associated phenotype, we turned to a well-established pituitary tumor cell line, the mouse corticotrope AtT20, previously shown to grow tumors after sc implantation in immunodeficient mice (Taguchi et al. 2006).

\section{Characterization of AtT20's SP and tumorigenic activity}

First, we examined whether the AtT20 cell line contains a SP. A verapamil-blockable Hoechst ${ }^{\text {low }}$ cell population was detected, amounting to $1.0 \% \pm 0.3$ of total cells ( $n=12 ;$ Fig. $3 A$ ). This AtT20 SP shows upregulated expression of the analyzed 'tumor stemness' genes $C d 44$ and $C x c r 4$ (Fig. 3B).

To study in vivo tumorigenic activity, we first verified the tumor-growing capacity of AtT20 cells in SCID mice. Sc injection of $5 \times 10^{5}$ cells results in a gradually developing tumor (Supplementary Fig. S5A), palpable after 15-20 days and further expanding in volume until the mouse becomes moribund, most likely due to corticoid overproduction because of enhanced adrenal stimulation by the AtT20produced ACTH (Taguchi et al. 2006). A SP remains present in the AtT20-derived xenograft tumors (as analyzed after 50-55 days), although the proportion is lower than in the cell line in culture $(0.5 \%$ versus $1 \% ; \mathrm{n}=3$ ).

SP and MP cells were then sorted by FACS from cultured AtT20 cells, and varying numbers (10 000, 5000 and 1000 cells) sc injected into SCID mice. Although all cell populations induced tumor growth, SP-derived tumors expanded faster (Supplementary Fig. S5B) and/or became larger (Fig. 3C 
and Supplementary Fig. S5B) when compared to MP-derived tumors. The SP cells developed a tumor with reconstitution of the SP/MP profile $(0.5 \% \mathrm{SP} ; \mathrm{n}=2)$ whereas the MP cells generated tumors with a lower SP portion (0.2\%; $n=2$ ). Together, our results provide indications that the AtT20 SP has tumor-proliferative dominance, and that TSC(-like cells) are enriched, although not exclusively segregated, in the SP.

\section{Effects of EMT-regulatory pathways in the AtT20 cell line}

As described above, the transcriptomic data of the human pituitary adenomas support the presence of an EMT process in the (p)SP. Therefore, we tested the impact of two important EMTregulatory pathways (De Craene \& Berx 2013), i.e. of TGF $\beta$ and Cxcr4, in the AtT20 cell line. Moreover, Cxcr4 has been identified as a marker of $\operatorname{csC}$ (-like cells) in various types of cancer (Hermann et al. 2007; Vankelecom \& Gremeaux 2010; Clevers 2011). As mentioned above, its expression is upregulated in the human pituitary adenoma pSP and the AtT20 SP (Table 3, Fig. 1E and Fig. 3B). Of note, these studies could not be performed with primary human pituitary adenoma cells since these cells cannot efficiently be kept in culture and do not grow (well) in vitro (Hofland \& Lamberts 2002).

Treatment of AtT20 cells with TGF $\beta 1$ for $72 \mathrm{hr}$ significantly stimulated the expression of EMT factors Snai2 and Vim, while there was a clear upward trend for Snai1 and Cxcr4 (Fig. 4A). However, TGF $\beta 1$ treatment did not significantly enhance the motility of AtT20 cells, which is an expected functional consequence of EMT (Fig. 4B). Treatment of AtT20 cells in culture with TGF $\beta 1$ did not significantly increase the SP proportion $(1.2 \% \pm 0.1$ versus $1.0 \% \pm 0.3$ in control culture; $n=3 ; p>0.05)$. Along the same line, pretreatment of AtT20 cells with TGF $\beta 1$ did not lead to a higher tumor-growing capacity when Sc transplanted in SCID mice, neither regarding onset, nor regarding progression (volume expansion) of the tumor (Supplementary Fig. S5C). 
To analyze the involvement of the Cxcr4 pathway, we treated developing AtT20 xenograft

tumors in SCID mice with the Cxcr4 antagonist AMD3100. Interestingly, tumors injected with AMD3100 grew at a slower rate and remained smaller than vehicle-injected tumors (Fig. 4C).

We further observed that AMD3100 significantly reduced the migratory activity of AtT20 cells as analyzed in vitro (Fig. 4B), thus suggesting an impact on EMT. However, AMD3100 treatment did not significantly affect the expression level of the EMT-associated genes Zeb2, Snai1, Snai2 (although a downward trend was observed), Vim and Cdh1, and of the CSC-associated marker Cd44, as analyzed in the xenograft tumors after 20 days of treatment (Fig. 4D). In vitro, 72-hr AMD3100 treatment did also not affect expression levels of these genes, and had no significant effect (although tendancy) on the proportion of the SP $(0.5 \% \pm 0.3$ versus $0.9 \% \pm 0.2$ in control; $n=3 ; p>0.05)$. Of note, there was a small increase in Cxcr4 expression in the AMD3100-treated xenograft tumors (Fig. 4D); upregulation of CxCr4 after AMD3100 treatment has also been reported in other tumors, supposedly due to adaptation of the tumor to sustained Cxcr4 signal inhibition (Domanska et al. 2012). Together, EMT genes - at least the ones analyzed - do not seem to be involved in the AMD3100-induced inhibition of cell motile activity and of xenograft tumor growth (at least as examined after 20 days of treatment). To search for possible other mechanisms of tumor growth reduction, cell viability and proliferation were evaluated. Treatment of cultured AtT20 cells with AMD3100 results in a 2- to 3fold increase in dying/dead cells (from 2-4\% in control to 8-11\% after AMD3100 treatment; Fig. 4E). In analogy, AMD3100 augments the number of AtT20 cells that go into apoptosis (about 2-fold; Fig. 4F). However, no difference was found (anymore) in the number of apoptotic cells after 20-day AMD3100 treatment in vivo (data not shown). Treatment of cultured AtT20 cells with AMD3100 also reduces the proportion of proliferating cells (from about 90 to $60 \%$ after $72 \mathrm{hr}$; Fig. $4 \mathrm{G}$ ). From these in vitro data, it is assumed that the tumor-growth inhibitory effect of AMD3100 at least partially involves a reduction in cell viability and proliferation. From our data so far, there are no indications yet that EMT is also implicated. 


\section{Pituitary tumorigenesis and pituitary stem cells}

In addition to the finding of SOX2 expression in tumorsphere cells, our microarray analysis also revealed upregulated gene expression of SOX2 in the adenoma pSP (>1.5-fold in 3 of the 5 human pituitary tumors analyzed; $p<0.05)$. Interestingly, the AtT20 SP also shows higher expression of Sox2 (as compared to the MP; Supplementary Fig. S6A). A comparable finding was observed in an additional pituitary tumor cell line, the rat lactosomatotrope $\mathrm{GH} 3$, also containing a SP $(0.5 \% \pm 0.05$; n=18) (Supplementary Fig. S6A-B). Sox2 is a stemness factor which also marks the recently identified stem cells of the pituitary gland (Chen et al. 2009). In general, a link may exist between CSC/TSC of tumors in organs and the resident stem cells, as recently supported in several cancers (Barker et al. 2009; Llaguno et al. 2009; Zhu et al. 2009; Mulholland et al. 2010; Vankelecom \& Gremeaux 2010; Clevers 2011; Lapouge et al. 2011; Chen et al. 2012; Schepers et al. 2012; Boumahdi et al. 2014; Vankelecom \& Chen 2014; Vanner et al. 2014).

To further explore the pituitary stem cells in the gland's tumors, we turned to the dopamine D2 receptor knock out $\left(\operatorname{Drd2}^{-/}\right)$mouse model (Cristina et al. 2006). In the pituitary of $\operatorname{Drd}^{-1}$ female mice, prolactinomas gradually develop starting from 6-8 months of age, as visible by MRI and after necropsy (Supplementary Fig. S7A). The $\mathrm{CD} 31^{-} / \mathrm{CD} 45^{-} \mathrm{SP}(\mathrm{pSP})$ proportion in the tumor-bearing AP from $\operatorname{Drd} 2^{-/}$mice $(1.7 \% \pm 0.3 ; \mathrm{n}=5$; Supplementary Fig. S7B $)$ is higher than from heterozygous $\mathrm{Drd} 2^{+-}$ $(1.4 \% \pm 0.6 ; n=2)$ and wildtype $\operatorname{Drd}^{+/+}$control littermates $(1.3 \% \pm 0.2 ; n=2)$. Calculated to absolute cell numbers (see Materials and Methods), the $\operatorname{Drd} 2^{-/}$AP contains about 10-fold more pSP cells than the control mice (Fig. 5A). Similarly, the absolute number of colony-forming cells (also often used to in-vitro investigate TSC activity) is higher in $\operatorname{Drd2}^{-/}$than $\mathrm{Drd}^{+/-}$pituitaries (3.9-fold $\pm 0.7 ; \mathrm{n}=3$ ). In addition, colonies that develop from the $\mathrm{Drd}^{-}$p pituitary are generally larger in size and more smoothly shaped than the colonies from the heterozygous mice (Supplementary Fig. S7C).

We next examined the prolactinoma-bearing pituitary of $\mathrm{Drd}^{-}{ }^{-}$mice for Sox2 $2^{+}$cells. From countings in dissociated APs (see Materials and Methods), the absolute number of Sox $2^{+}$cells is higher in the $\mathrm{Drd}^{-/-}$AP when compared to the wildtype gland (2.4-fold $\pm 0.6 ; n=3$ ) (Fig. 5B). At least 
615 part of the increase in Sox $2^{+}$cells is due to higher proliferative activity; whereas proliferating $\left(\mathrm{Ki}^{+} \mathrm{7}^{+}\right)$ 616 Sox $2^{+}$cells are virtually absent in wildtype Drd2 ${ }^{+/+}$AP at the ages tested (6 to 12 months), double 617 Sox $2^{+} / \mathrm{Ki}_{67} 7^{+}$cells are more readily observed in Drd2 ${ }^{-/}$AP (Fig. 5C). Furthermore, as also seen before 618 (Chen et al. 2009; Fu et al. 2012; Gremeaux et al. 2012), Sox2-immunoreactive signal is not only 619 found in the expected location of the nucleus (nuclear-Sox $2^{+}$or $n$ Sox $2^{+}$cells), but some cells show 620 Sox $2^{+}$signal in the cytoplasm (cytoplasmic-Sox $2^{+}$or $\mathrm{cSox}^{+}$cells). The $\mathrm{Drd}^{-/}$cSox $2^{+}$cells show a 621 higher increase than the $\mathrm{nSox} 2^{+}$cells when compared to $\operatorname{Drd} 2^{+/+}$wildtype pituitaries (3.1-fold \pm 0.3 622 and 2.3-fold \pm 0.7 , respectively; Fig. 5B-C). In situ, Sox $2^{+}$cells in the $D r d 2^{-}$pituitary are found in the 623 marginal zone bordering the cleft, which is not different from wildtype (Fig. 5D and Supplementary

624 625 626 627 628 629 630 Fig. S7D). On top of this location, frequent clusters of Sox $2^{+}$cells are observed within the $\mathrm{PRL}^{+}$tumor cell mass in the $\mathrm{Drd}^{\%}$ pituitary (Fig. 5D and Supplementary Fig. S7D). In the wildtype gland, Sox ${ }^{+}$ cell clusters are also observed spread within the endocrine AP parenchyma (Fig. 5D and Supplementary Fig. S7D). Double Sox ${ }^{+} / \mathrm{PRL}^{+}$cells were not observed in neither of the pituitary phenotypes. Taken together, the number of Sox $2^{+}$cells clearly increases in $\operatorname{Drd} 2^{--}$versus wildtype pituitary, but their overall appearance in the putative stem cell niches seems not very different. 


\section{DISCUSSION}

Adenomas represent the most frequent pathology of the pituitary gland. Despite extensive research, not much is known about the mechanisms underlying pituitary tumor pathogenesis.

In the present study, we demonstrate the existence of a SP in different models of pituitary tumor including human adenomas, mouse tumors and cell lines. During the last decade, a SP has been identified in many tumor types and cell lines, and was often found enriched in cells with CSC or CSC-like phenotype or activity (Patrawala et al. 2005; Wu \& Alman 2008; Kato et al. 2010; Britton et al. 2012; Moti et al. 2014). The majority of these studies looked for CSC in malignant cancers. Our study is among the first to identify a SP in benign tumors (Wu et al. 2007). The pituitary adenoma SP still represents a heterogeneous population, similar to the SP in other tumors as well as in healthy tissues (Pfister et al. 2005; Uezumi et al. 2006). In a previous study we also detected endothelial-type cells in the SP of the normal (mouse) pituitary; further purification led to the identification of pituitary stem cells (Chen et al. 2009). The endothelial-type SP cells of the pituitary tumors may represent a progenitor phenotype, driving angiogenesis during tumor expansion. Presence of endothelial progenitor cells in pituitary adenomas has indeed been suggested based on detection of CD133, CD34, NESTIN and VEGFR2 in non-hormonal and non-folliculostellate cells of the tumors (Yunoue et al. 2011). Of note, the expression picture distilled from the total adenoma SP was found to be largely reconfirmed in the purified $\mathrm{CD}^{-} / \mathrm{CD}^{-} 5^{-} \mathrm{SP}(\mathrm{pSP})$. Also other studies have demonstrated that expression characteristics of minority CSC fractions can already surface in still mixed populations (Eppert et al. 2011).

Several genes upregulated in the ( $\mathrm{p}) \mathrm{SP}$ are associated with a 'tumor stemness' phenotype as also reported for the SP in other tumors (Patrawala et al. 2005; Wu \& Alman 2008; Kato et al. 2010; Britton et al. 2012; Moti et al. 2014). In addition, the NOTCH, WNT and TGF $\beta / B M P$ pathways represent not only '(tumor) stemness' signaling systems but also regulatory circuits well known for their critical role in pituitary embryonic development (Zhu et al. 2007; Vankelecom 2010). Also the upregulated expression of $\mathrm{NOTCH} 2$ may be remarkable in this sense because particularly this 
member of the Notch receptor family is highly expressed in the progenitor cells of Rathke's pouch, the embryonic pituitary anlage (Zhu et al. 2007; Vankelecom 2010). This embryonic link may be in line with the idea that CSC recapitulate aspects of embryonic development. Also other studies suggested the involvement of NOTCH and WNT signaling in pituitary tumorigenesis as concluded from transcriptomic analysis of unfractionated adenomas (Moreno et al. 2005). Furthermore, the upregulation of HIF2 $\alpha$ in the SP may be of importance; in other tumors like glioma, HIF2 $\alpha$ regulates the tumorigenic capacity of the CSC fraction (Das et al. 2008). Hypoxia is known to stimulate CXCR4 expression (De Craene \& Berx 2013)] which is indeed found upregulated in the pituitary tumor (p)SP. In many cancer types CXCR4 has been advanced as a marker of CSC, and the pathway is known to play a role in CSC activity (Hermann et al. 2007; Vankelecom \& Gremeaux 2010; Clevers 2011). Of further note, the epidermal growth factor receptor-associated protein-8 (EPS8) is also overexpressed in the pSP ( 4 of the 5 adenomas, $p<0.05$; Supplementary Table S8). This oncoprotein has previously been found upregulated in multiple pituitary tumor subtypes in which it mediates survival, proliferation and tumorigenicity (Xu et al. 2009a). Moreover, the accompanying receptor EGFR is also upregulated and is involved in tumor cell migration in some cancers (Hölsken et al. 2011). Finally, our expression data suggest that the PI3/Akt/mTOR/PTEN pathway is also enriched in the adenoma SP (data not shown). This pathway has been proposed to play a role in pituitary tumorigenesis (Dworakowska et al. 2009). Moreover, CXCR4 and PI3K/Akt are interconnected; it has been shown that paracrine/autocrine activation of CXCR4 signaling provokes Akt-mediated prosurvival of glioblastoma CSC (Rubin et al. 2003; Gatti et al. 2013).

It should be noticed that the expression pattern in the PSP does only minimally overlap with the set of genes (CD133, NESTIN, CD90/THY1, OCT4, MSI, JAG2, NOTCH4, DLL1) recently identified as upregulated in candidate pituitary TSC (so-called 'pituitary adenoma stem-like cells' or PASCs), which were obtained by sphere-like culture (Xu et al. 2009b). In our study, only NOTCH4, DLL1 and NESTIN are found overexpressed, with NOTCH4 and DLL1 only upregulated in the total SP and not in the pSP. Moreover, expression levels of the multidrug transporter genes BCRP1 (ABCG2) and MDR1 (ABCB1) 
were reported not to be upregulated in the PASCs (Xu et al. 2009b). These divergent results may be mainly explained by the use of cultured cells (Xu et al. 2009b) versus cells obtained directly from the tumor (present study) (further commented on in Vankelecom 2012; Vankelecom \& Chen 2014).

In a recent study (Donangelo et al. 2014), candidate TSC were proposed to exist in pituitary tumors developing in $R b^{+/-}$mice. These tumors differ from typical pituitary adenomas (i.e. of the AP) since arising in the intermediate lobe (IL) of the gland. Stem cell antigen 1 (Sca1)-immunoreactive cells sorted from these IL tumors showed higher sphere-forming capacity when compared to the Sca1 cells, as well as increased expression of Sox 2 and nestin, and tumor-growth advantage after injection of a high number of cells $\left(10^{5}\right)$ into the brain striatum of NOD-SCID ${ }^{\mathrm{IL2RY}-\mathrm{-}}$ mice. Before, we have shown that pituitary 'stemness' is rather accompanied by the absence of Sca1 and that Sca1 expression is mainly found in the endothelial fraction of the SP (Chen et al. 2009), later supported by the detection of Sca1 in progenitor cells of endothelial or mesenchymal origin in mouse pituitary cell lines (Mitsuishi et al. 2013). Thus, Sca1 expression may represent a difference in the signature of the IL tumor TSC and the normal pituitary stem cells. Alternatively, Sca $1^{+}$cells from the IL tumors may also include endothelial progenitor cells $\left(\mathrm{CD} 1^{+}\right.$cells were not removed from the $\mathrm{Sca}^{+}$fraction) which would facilitate tumor xenograft development by providing angiogenic support, and which may be an (additional) explanation for the tumor-growth advantage. Similar to our findings, the $\mathrm{Sca}^{+}$fraction did not fully retrieve the tumorigenic activity and Sca1 ${ }^{-}$cells also formed tumors (although to a lower extent). Intriguingly, in the majority of the xenograft tumors derived from the $\mathrm{Sca}^{+}$cell population, no Sca $1^{+}$cells could be detected anymore, which does not exactly fit with the definition of self-renewing CSC. It should also be remarked that Sca1 cannot be employed as a (potential) TSC marker in human pituitary adenomas since this gene (product) does not exist in man. In contrast to the highly penetrant $R b^{+-}$IL tumors (Donangelo et al. 2014), benign human pituitary adenomas (transplanted sc or subrenally) did not expand in mice whatever the mouse grade of immunodeficiency. Xu et al. (2009b) reported 'growth and reconstitution of the original tumor' from their PASC spheroids (as analyzed for $1 \mathrm{GH}-\mathrm{A}$ ) when implanted in the forebrain of NOD/SCID 
mice, but no clearly demarcated tumor or expansion was shown (further reviewed in Vankelecom 2012; Vankelecom \& Chen 2014).

Since the standard xenograft assay did not work starting form benign human pituitary adenoma, we further turned to in vitro TSC assays and to the well-established pituitary tumor AtT20 cell line. Cultured cell lines are often used as complementary paradigms to study (candidate) CSC. Moreover, in cell lines of multiple cancer types, the SP has been found to enrich for authentic or candidate CSC (Patrawala et al. 2005; Wu \& Alman 2008; Kato et al. 2010; Britton et al. 2012). First, we discovered that human pituitary adenomas contain self-renewing sphere-forming cells that express the stemness markers Sox2 and nestin, and that the sphere-initiating cells segregate to the pSP. In addition, the AtT20 cell line also contains a SP which was found to enrich for cells that are more tumorigenic (i.e. grow faster and larger tumors) than MP cells, that better reconstitute the tumor's original heterogeneity (SP/MP profile) - a further property of CSC -, and that express CSC-associated genes. The segregation of tumorigenic activity in the SP is not absolute as also observed in various other studies on CSC (Boumahdi et al. 2014; Vanner et al. 2014) and in the $R b^{+/-}$IL tumors as mentioned above (Donangelo et al. 2014).

The (p)SP identified also displays an expression pattern supportive of EMT occurring in that tumor compartment. In recent studies, CSC and EMT have been linked in that EMT acts as a major driver of CSC generation and activity (Mani et al. 2008; Morel et al. 2008; Kong et al. 2010; Pirozzi et al. 2011; Yoon et al. 2012; De Craene \& Berx 2013). In addition to being an argument in favor of the $\mathrm{CSC}$ (-like) phenotype of the pSP, the detection of EMT may also have implications for understanding pituitary tumor behavior. In several cancers, EMT, or EMT-driven CSC, are involved in expansion, invasion, resistance to hostile conditions (including therapy) and recurrence (Mani et al. 2008; Morel et al. 2008; Bertran et al. 2009; Kong et al. 2010; Pirozzi et al. 2011; De Craene \& Berx 2013). The GO enrichment picture including gene clusters associated with cell motility and migration, as well as the expression of chemotactic receptors like CXCR4 in the adenoma pSP further supports the migratory capacity. Noteworthy, highest relative expression levels in the pSP (and highest differences in pSP 
versus $\mathrm{pMP}$ ) of the EMT-associated genes ZEB2, SNAI2 and TWIST1 were found in the adenoma sample with the most aggressive character regarding invasion of neighbouring structures (PA 40 in Table 1). On the other hand, from the data of a limited number of tumors assessed for invasive character (i.e. PA03, 06, 07, 10, 15, 17, 19, 20, 22, 23, 33, 34, 35, 38, 40), no correlation emerged (yet) between invasiveness and SP proportion. The pSP compartment also expresses angiogenic factors which may suggest that TSC drive tumor angiogenesis to support the growth of the tumor. CSC may also contribute to neovascularization through transdifferentiation to endothelial cells as has been reported in glioblastoma (Dong et al. 2011). Processes such as EMT, angiogenesis and hypoxia are known to contribute to maintenance and regulation of CSC in interaction with their microenvironment.

Because human pituitary adenoma fails to grow not only in vivo but also in vitro (Hofland \& Lamberts 2002), EMT was further studied in the AtT20 cell line. The TGF $\beta$ pathway is known as an important regulator of EMT (Bertran et al. 2009; Pirozzi et al. 2011; De Craene \& Berx 2013). Although TGF $\beta$ activation stimulated expression of some EMT-regulatory and 'stemness'-associated genes, treatment of AtT20 did not enhance EMT-linked cell motility, neither did pretreatment induce faster or more pronounced xenograft tumor formation. Of note, the impact of the in vitro pretreatment may fade away during in vivo growth. In general, TGF $\beta$ is known to play a dual role in tumor pathogenesis: it may not only promote tumor progression (angiogenesis, invasion, metastasis) by stimulating tumorigenic activity and EMT (Mani et al. 2008; Bertran et al. 2009; Pirozzi et al. 2011; De Craene \& Berx 2013) but may also inhibit tumor growth by reducing cell proliferation (Ramsdell 1991; Tirino et al. 2013). We indeed observed a small tendency towards slower tumor growth after pretreatment of the AtT20 cells with TGF $\beta 1$ (see Supplementary Fig. S5C). Furthermore, it should be mentioned that AtT20 cells already display some mesenchymal character in basal conditions as concluded from their spindle-shaped morphology and their basic motility in the scratch assay (data not shown), which may explain the limitation to supplementarily activate a mesenchymal phenotype. Regarding the CXCR4 pathway as the second EMT-regulatory system tested, inhibition leads to 
reduction of AtT20 cell motility and of tumor growth. The latter finding is in line with a previous study showing that anti-CXCR4 treatment suppresses primary brain tumor growth, and that treatment of mice with AMD3100 results in decreased proliferation and invasion of the xenografted brain tumors, and in better survival of the animals (Rubin et al. 2003). In addition, activation of CXCR4 has been shown to stimulate cell proliferation in human pituitary adenoma cultures (Barbieri et al. 2008). Here, we show that the Cxcr4 pathway is involved in pituitary tumor growth in vivo. AMD3100 was found to induce AtT20 cell death and apoptosis, and to reduce cell proliferation (as analyzed in vitro), similar to findings by others in pituitary and other tumors (Barbieri et al. 2008; Gatti et al. 2013). Whether EMT is (also) implicated in the growth-inhibitory effect of AMD3100, is not clear yet; expression of the tested selection of EMT genes was not affected after long-term treatment in vivo (20 days) or short-term exposure in vitro (72 hr). EMT-associated genes different from the ones analyzed may still be involved (as e.g. described in breast CSC; Yoon et al. 2012). Neither activation of the TGF $\beta$ pathway nor inhibition of the Cxcr4 pathway significantly affected the SP proportion, although effects may be small and absence of an effect on proportion does not exclude a possible effect on the (molecular) activation status of the SP cells. Further studies are needed to shed more light on the mechanisms.

An important question in cancer research concerns the link of tumorigenesis (and CSC) with the tissue's own stem cells. In several types of cancer, it has been shown that tissue stem cells are at the origin of tumors and/or of CSC (Barker et al. 2009; Llaguno et al. 2009; Zhu et al. 2009; Mulholland et al. 2010; Lapouge et al. 2011; Chen et al. 2012; Schepers et al. 2012; Boumahdi et al. 2014; Vanner et al. 2014). On the other hand, stem cells may not directly be involved, but may become activated when a tumorigenic 'assault' is occurring in their tissue (Vankelecom \& Gremeaux 2010; Vankelecom \& Chen 2014). Here, we observed that the pSP, the Sox $2^{+}$and the colony-forming cells are increased in number when tumors are present in the pituitary, as analyzed in $\operatorname{Drd} 2^{-/}$mice in which prolactinomas develop within their natural microenvironment. Our findings suggest activation of the pituitary stem cell compartment during tumorigenesis with a rise in cell number. It should be noted 
that the populations identified may comprise both the 'normal' pituitary stem cells and the (potentially stem cell-derived) TSC or TSC-like cells. At present, it is not possible to distinguish between both on the basis of the properties analyzed (SP, Sox2 expression, colony formation). The fact that cell numbers and increments are not identical among the 3 populations (pSP, Sox $2^{+}$and colony-forming) suggests that they do not fully overlap, as has also been observed before (Chen et al. 2009; Fu et al. 2012). Moreover, more than one (cancer) stem cell population has also been detected in other tissues and tumors (see e.g. Zhu et al. 2014). The finding that these populations expand in number may indicate that the stem cells react during tumorigenesis and that they may play a role in the pathogenic process. Of note, the higher increase in cytoplasmic-Sox $2^{+}$cells in the tumorous pituitary might support a higher differentiation rate towards tumor $\mathrm{PRL}^{+}$cells (Chen et al. 2009; Fu et al. 2012; Gremeaux et al. 2012). In addition, Sox $2^{+}$cell clusters were often observed within the PRL ${ }^{+}$ tumor cell masses, although they also occur scattered over the parenchyma in the normal AP. Whether existing clusters are entrapped during tumor formation, or whether they play a more active role in the tumorigenic process, either directly (as origin) or indirectly (as tumor-inducing or -tropic), needs to be further clarified (e.g. by lineage tracing). In a recent study, lineage tracing did not detect a direct link of descent between transgenically $W n t / \beta$-catenin-induced craniopharyngioma in the pituitary and the Sox $2^{+}$stem cells. Instead, findings suggested that the Sox $2^{+}$stem cells rather act as paracrine tumor-activating cells (Andoniadou et al. 2013). Adamantinomatous craniopharyngioma is a typically pediatric tumor likely originating from ectopic remnants of Rathke's pouch, and thus different from the typical AP tumors. The transcription factor Sox2 itself may also play a role in pituitary tumorigenesis, e.g. when not properly shut down by the tumor suppressor p27 (at least as demonstrated for IL tumors; reviewed in Vankelecom and Chen, 2014). In addition, Sox2 can act as an oncogene in tissues where it is expressed in the putative stem cells (e.g. lung, oesophagus and skin) (Arnold et al. 2011; Boumahdi et al. 2014). Also overexpression of other pituitary stem cell factors (like Prop1) from the early Rathke's pouch state onwards, may lead to tumor formation in the gland (reviewed in Vankelecom and Chen, 2014). Again, Prop1 is not found within the tumors but in 
813 non-neoplastic regions surrounding the lesions, suggesting that Prop1 overexpression does not 814 generate tumor-driving stem cells but rather trophically supporting cells.

815 In conclusion of our study, we identified a SP in pituitary tumor displaying TSC-associated 816 molecular and functional characteristics. Identification of this cell population may eventually help to 817 better understand pituitary tumor pathogenesis, and may have an impact on clinical management of 818 the disease. The global molecular profile of the PSP may thereby serve as a valuable source to 819 identify potentially interesting therapeutic targets for further examination. 
821 DECLARATION OF INTERESTS

822 The authors declare that there is no conflict of interest that could be perceived as prejudicing

823 the impartiality of the research report.

824 
825

826

827

828

829

830

831

832

833

834

\section{FUNDING}

This work has been supported by research grants from the KU Leuven (Research Fund, BOF) and from the Fund for Scientific Research (FWO) Flanders (Belgium), by a joint research grant between FWO and the Ministry of Science and Technology of China (MOST; 2012DFG32000), by a joint travel grant between FWO and the Ministry of Science, Technology and Productive Innovation (MinCyt) of Argentina, and by collaborative efforts in the context of grants from the National Natural Science Foundation (NSF) of China (30500248 and 81300641). FM and HR obtained a PhD Fellowship from the IWT (Agency for Innovation by Science and Technology; Flanders, Belgium), and LG from the FWO. 
835

836

837

838

839

840

841

842

843

844

845

846

847

\section{ACKNOWLEDGMENTS}

We dedicate this paper to Vik Van Duppen (Stem Cell Institute - SCIL, KU Leuven), our FACS expert who tragically passed away in 2013. Without his proficient help, SP analysis would never have been developed to a successful technique in our laboratory. We also thank Rob Van Rossom (SCIL) for his help with FACS analysis and sorting, and the VIB Nucleomics Core (www.nucleomics.be) for their expert assistance in microarray analysis. We are further indebted to Yvonne Van Goethem (HV lab) for technical assistance, to Jasper Wouters en Anke Van den broeck (former PhD students in the HV lab) for their valuable input and discussions, and to the Department of Imaging and Pathology and Biobank (Dr. Sciot; University Hospitals Leuven). We also thank the 'Molecular Small Animal Imaging Centre' (MoSAIC, KU Leuven) for their valued guidance in pituitary imaging using MRI, the $\mathrm{CIC}$ for use of the Zeiss confocal microscope and InfraMouse (KU Leuven-VIB, Hercules type 3 grant) for use of the Leica microscope. 


\section{ReferenCES}

Andoniadou CL, Matsushima D, Mousavy Gharavy SN, Signore M, Mackintosh Al, Schaeffer M, Gaston-Massuet C, Mollard P, Jacques TS, Le Tissier P et al. 2013 Sox2(+) stem/progenitor cells in the adult mouse pituitary support organ homeostasis and have tumor-inducing potential. Cell Stem Cell 13 433-445. (doi:10.1016/j.stem.2013.07.004)

Arnold K, Sarkar A, Yram MA, Polo JM, Sengupta S, Seandel M, Geijsen N \& Hochedlinger K 2011 Sox $2+$ adult stem/progenitor cells are important for tissue regeneration and survival of mice. Cell Stem Cell 9 317-329. (doi:10.1016/j.stem.2011.09.001.Sox2)

Barbieri F, Bajetto A, Stumm R, Pattarozzi A, Porcile C, Zona G, Dorcaratto A, Ravetti J-L, Minuto F, Spaziante R et al. 2008 Overexpression of stromal cell-derived factor 1 and its receptor CXCR4 induces autocrine/paracrine cell proliferation in human pituitary adenomas. Clinical Cancer Research : An Official Journal of the American Association for Cancer Research 14 5022-5032. (doi:10.1158/1078-0432.CCR-07-4717)

Barker $\mathrm{N}$, Ridgway R a, van Es JH, van de Wetering $\mathrm{M}$, Begthel $\mathrm{H}$, van den Born $\mathrm{M}$, Danenberg $\mathrm{E}$, Clarke AR, Sansom OJ \& Clevers H 2009 Crypt stem cells as the cells-of-origin of intestinal cancer. Nature. 457 608-611.

Bertran E, Caja L, Navarro E, Sancho P, Mainez J, Murillo MM, Vinyals A, Fabra A \& Fabregat I 2009 Role of CXCR4/SDF-1 alpha in the migratory phenotype of hepatoma cells that have undergone epithelial-mesenchymal transition in response to the transforming growth factor-beta. Cellular Signalling 21 1595-1606. (doi:10.1016/j.cellsig.2009.06.006)

Boumahdi S, Driessens G, Lapouge G, Rorive S, Nassar D, Le Mercier M, Delatte B, Caauwe A, Lenglez $S$, Nkusi E et al. 2014 SOX2 controls tumour initiation and cancer stem-cell functions in squamous-cell carcinoma. Nature. (doi:10.1038/nature13305)

Britton KM, Eyre R, Harvey IJ, Stemke-Hale K, Browell D, Lennard TWJ \& Meeson a P 2012 Breast cancer, side population cells and ABCG2 expression. Cancer Letters 323 97-105. (doi:10.1016/j.canlet.2012.03.041)

Chen J, Hersmus N, Van Duppen V, Caesens P, Denef C \& Vankelecom H 2005 The adult pituitary contains a cell population displaying stem/progenitor cell and early embryonic characteristics. Endocrinology 146 3985-3998. (doi:10.1210/en.2005-0185)

Chen J, Gremeaux L, Fu Q, Liekens D, Van Laere S \& Vankelecom H 2009 Pituitary progenitor cells tracked down by side population dissection. Stem Cells (Dayton, Ohio) 27 1182-1195. (doi:10.1002/stem.51)

Chen J, Li Y, Yu T-S, McKay RM, Burns DK, Kernie SG \& Parada LF 2012 A restricted cell population propagates glioblastoma growth after chemotherapy. Nature 488 522-526. (doi:10.1038/nature11287)

Clevers H 2011 The cancer stem cell: premises, promises and challenges. Nature Medicine $17313-$ 319. (doi:10.1038/nm.2304) 
De Craene B \& Berx G 2013 Regulatory networks defining EMT during cancer initiation and progression. Nature Reviews. Cancer 13 97-110. (doi:10.1038/nrc3447)

Cristina C, Rubinstein M, Low MJ \& Becu-Villalobos D 2006 Dopaminergic D2 Receptor Knockout Mouse: An Animal Model of Prolactinoma. Frontiers of Hormone Research 35 50-63.

Daly AF, Tichomirowa M a \& Beckers A 2009 The epidemiology and genetics of pituitary adenomas. Best Practice \& Research. Clinical Endocrinology \& Metabolism 23 543-554. (doi:10.1016/j.beem.2009.05.008)

Das B, Tsuchida R, Malkin D, Koren G, Baruchel S \& Yeger H 2008 Hypoxia enhances tumor stemness by increasing the invasive and tumorigenic side population fraction. Stem Cells (Dayton, Ohio) 26 1818-1830. (doi:10.1634/stemcells.2007-0724)

Domanska UM, Timmer-Bosscha H, Nagengast WB, Munnink THO, Kliphuis NM \& Huls G 2012 CXCR4 Inhibition with AMD3100 Sensitizes Prostate Cancer to docetaxel chemotherapy. Neoplasia 14 709-718. (doi:10.1593/neo.12324)

Donangelo I, Ren S-G, Eigler T, Svendsen C \& Melmed S 2014 Sca1-positive murine pituitary adenoma cells show tumor growth advantage. Endocrine-Related Cancer 21 203-216. (doi:10.1530/ERC13-0229)

Dong J, Zhao Y, Huang Q, Fei X, Diao Y, Shen Y, Xiao H, Zhang T, Lan Q \& Gu X 2011 Glioma stem/progenitor cells contribute to neovascularization via transdifferentiation. Stem Cell Reviews 7 141-152. (doi:10.1007/s12015-010-9169-7)

Dworakowska D, Wlodek E, Leontiou CA, Igreja S, Cakir M, Teng M, Prodromou N, Góth MI, Grozinsky-Glasberg S, Gueorguiev M et al. 2009 Activation of RAF/MEK/ERK and $\mathrm{PI} 3 \mathrm{~K} / \mathrm{AKT} / \mathrm{mTOR}$ pathways in pituitary adenomas and their effects on downstream effectors. Endocrine-Related Cancer 16 1329-1338.

Eppert K, Takenaka K, Lechman ER, Waldron L, Nilsson B, van Galen P, Metzeler KH, Poeppl A, Ling V, Beyene J et al. 2011 Stem cell gene expression programs influence clinical outcome in human leukemia. Nature Medicine 17 1086-1093. (doi:10.1038/nm.2415)

Fu Q, Gremeaux L, Luque RM, Liekens D, Chen J, Buch T, Waisman A, Kineman R \& Vankelecom H 2012 The Adult Pituitary Shows Stem/Progenitor Cell Activation in Response to Injury and Is Capable of Regeneration. Endocrinology 153 1-12. (doi:10.1210/en.2012-1152)

Galland F, Lacroix L, Saulnier P, Dessen P, Meduri G, Bernier M, Gaillard S, Guibourdenche J, Fournier T, Evain-Brion $D$ et al. 2010 Differential gene expression profiles of invasive and non-invasive non-functioning pituitary adenomas based on microarray analysis. Endocrine-Related Cancer 17 361-371. (doi:10.1677/ERC-10-0018)

Gatti M, Pattarozzi A, Bajetto A, Würth R, Daga A, Fiaschi P, Zona G, Florio T \& Barbieri F 2013 Inhibition of CXCL12/CXCR4 autocrine/paracrine loop reduces viability of human glioblastoma stem-like cells affecting self-renewal activity. Toxicology 314 209-220. (doi:10.1016/j.tox.2013.10.003) 
Gremeaux L, Fu Q, Chen J \& Vankelecom H 2012 Activated phenotype of the pituitary stem/progenitor cell compartment during the early-postnatal maturation phase of the gland. Stem Cells and Development 20 801-813.

Hermann PC, Huber SL, Herrler T, Aicher A, Ellwart JW, Guba M, Bruns CJ \& Heeschen C 2007 Distinct populations of cancer stem cells determine tumor growth and metastatic activity in human pancreatic cancer. Cell Stem Cell 1 313-323. (doi:10.1016/j.stem.2007.06.002)

Hofland ப \& Lamberts W 2002 Pituitary gland tumors. In Human Cell Culture, pp 149-159. (doi:10.1007/s00292-003-0625-x)

Hölsken A, Gebhardt M, Buchfelder M, Fahlbusch R, Blümcke I \& Buslei R 2011 EGFR signaling regulates tumor cell migration in craniopharyngiomas. Clinical Cancer Research : An Official Journal of the American Association for Cancer Research 17 4367-4377. (doi:10.1158/10780432.CCR-10-2811)

Kato K, Takao T, Kuboyama A, Tanaka Y, Ohgami T, Yamaguchi S, Adachi S, Yoneda T, Ueoka Y, Kato K et al. 2010 Endometrial cancer side-population cells show prominent migration and have a potential to differentiate into the mesenchymal cell lineage. The American Journal of Pathology 176 381-392. (doi:10.2353/ajpath.2010.090056)

Kong D, Banerjee S, Ahmad A, Li Y, Wang Z, Sethi S \& Sarkar FH 2010 Epithelial to mesenchymal transition is mechanistically linked with stem cell signatures in prostate cancer cells. PloS One 5 e12445. (doi:10.1371/journal.pone.0012445)

Lapouge G, Youssef KK, Vokaer B, Achouri Y, Michaux C, Sotiropoulou P a \& Blanpain C 2011 Identifying the cellular origin of squamous skin tumors. Proceedings of the National Academy of Sciences of the United States of America 108 7431-7436. (doi:10.1073/pnas.1012720108)

Llaguno SA, Chen J, Kwon C, Jackson EL, Li Y, Burns DK, et al. 2009 Malignant Astrocytomas Originate from Neural Stem/Progenitor Cells in a Somatic Tumor Suppressor Mouse Model. Cancer Cell 15 45-56.

Mani S a, Guo W, Liao M-J, Eaton EN, Ayyanan A, Zhou AY, Brooks M, Reinhard F, Zhang CC, Shipitsin $M$ et al. 2008 The epithelial-mesenchymal transition generates cells with properties of stem cells. Cell 133 704-715. (doi:10.1016/j.cell.2008.03.027)

Melmed S 2011 Pathogenesis of pituitary tumors. Nature Reviews. Endocrinology 7 257-266. (doi:10.1038/nrendo.2011.40)

Mitsuishi H, Kato T, Chen M, Cai L-Y, Yako H, Higuchi M, Yoshida S, Kanno N, Ueharu H \& Kato Y 2013 Characterization of a pituitary-tumor-derived cell line, TtT/GF, that expresses Hoechst efflux ABC transporter subfamily G2 and stem cell antigen 1. Cell and Tissue Research 354 563-572. (doi:10.1007/s00441-013-1686-7)

Morel A-P, Lièvre M, Thomas C, Hinkal G, Ansieau S \& Puisieux A 2008 Generation of breast cancer stem cells through epithelial-mesenchymal transition. PloS One 3 e2888. (doi:10.1371/journal.pone.0002888)

Moreno CS, Evans C-O, Zhan X, Okor M, Desiderio DM \& Oyesiku NM 2005 Novel molecular signaling and classification of human clinically nonfunctional pituitary adenomas identified by gene 
expression profiling and proteomic analyses. Cancer Research 65 10214-10222. (doi:10.1158/0008-5472.CAN-05-0884)

Moti N, Malcolm T, Hamoudi R, Mian S, Garland G, Hook CE, Burke G a a, Wasik M a, Merkel O, Kenner L et al. 2014 Anaplastic large cell lymphoma-propagating cells are detectable by side population analysis and possess an expression profile reflective of a primitive origin. Oncogene 1-10. (doi:10.1038/onc.2014.112)

Mulholland DJ, Xin L, Morim A, Lawson D, Witte O, Wu H 2010 LSC Stem/Progenitors Are Tumor Initiating Cells in the Pten Null Prostate Cancer Model. Cancer Research 69 8555-8562.

Patrawala L, Calhoun T, Schneider-Broussard R, Zhou J, Claypool K \& Tang DG 2005 Side population is enriched in tumorigenic, stem-like cancer cells, whereas ABCG2+ and ABCG2- cancer cells are similarly tumorigenic. Cancer Research 65 6207-6219. (doi:10.1158/0008-5472.CAN-05-0592)

Pfister O, Mouquet F, Jain M, Summer R, Helmes M, Fine A, Colucci WS \& Liao R 2005 CD31- but Not CD31+ cardiac side population cells exhibit functional cardiomyogenic differentiation. Circulation Research 97 52-61. (doi:10.1161/01.RES.0000173297.53793.fa)

Pirozzi G, Tirino V, Camerlingo R, Franco R, La Rocca A, Liguori E, Martucci N, Paino F, Normanno N \& Rocco $G 2011$ Epithelial to mesenchymal transition by TGF $\beta$-1 induction increases stemness characteristics in primary non small cell lung cancer cell line. PloS One 6 e21548. (doi:10.1371/journal.pone.0021548)

Ramsdell JS 1991 Transforming growth factor-alpha and -beta are potent and effective inhibitors of GH4 pituitary tumor cell proliferation. line. Endocrinology 128 1981-1990.

Rubin JB, Kung AL, Klein RS, Chan J a, Sun Y, Schmidt K, Kieran MW, Luster AD \& Segal R a 2003 A small-molecule antagonist of CXCR4 inhibits intracranial growth of primary brain tumors. Proceedings of the National Academy of Sciences of the United States of America $10013513-$ 13518. (doi:10.1073/pnas.2235846100)

Schepers AG, Snippert HJ, Stange DE, van den Born M, van Es JH, van de Wetering M \& Clevers H 2012 Lineage tracing reveals Lgr5+ stem cell activity in mouse intestinal adenomas. Science (New York, N.Y.) 337 730-735. (doi:10.1126/science.1224676)

Taguchi T, Takao T, Iwasaki Y, Nishiyama M, Asaba K \& Hashimoto K 2006 Suppressive effects of dehydroepiandrosterone and the nuclear factor-kappaB inhibitor parthenolide on corticotroph tumor cell growth and function in vitro and in vivo. The Journal of Endocrinology 188 321-331. (doi:10.1677/joe.1.06418)

Tirino V, Camerlingo R, Bifulco K, Irollo E, Montella R, Paino F, Sessa G, Carriero M V, Normanno N, Rocco G et al. 2013 TGF- $\beta 1$ exposure induces epithelial to mesenchymal transition both in CSCs and non-CSCs of the A549 cell line, leading to an increase of migration ability in the CD133+ A549 cell fraction. Cell Death \& Disease 4 e620. (doi:10.1038/cddis.2013.144)

Uezumi A, Ojima K, Fukada S, Ikemoto M, Masuda S, Miyagoe-Suzuki Y \& Takeda S 2006 Functional heterogeneity of side population cells in skeletal muscle. Biochemical and Biophysical Research Communications 341 864-873. (doi:10.1016/j.bbrc.2006.01.037) 
Vankelecom H 2010 Pituitary stem/progenitor cells: embryonic players in the adult gland? The European Journal of Neuroscience 32 2063-2081. (doi:10.1111/j.1460-9568.2010.07523.x)

Vankelecom H 2012 Pituitary stem cells drop their mask. Current Stem Cell Research \& Therapy 7 3671.

Vankelecom H \& Chen J 2014 Pituitary stem cells: where do we stand? Molecular and Cellular Endocrinology 385 2-17. (doi:10.1016/j.mce.2013.08.018)

Vankelecom H \& Gremeaux L 2010 Stem cells in the pituitary gland: A burgeoning field. General and Comparative Endocrinology 166 478-488. (doi:10.1016/j.ygcen.2009.11.007)

Vanner RJ, Remke M, Gallo M, Selvadurai HJ, Coutinho F, Lee L, Kushida M, Head R, Morrissy S, Zhu X et al. 2014 Quiescent Sox2(+) Cells Drive Hierarchical Growth and Relapse in Sonic Hedgehog Subgroup Medulloblastoma. Cancer Cell 26 33-47. (doi:10.1016/j.ccr.2014.05.005)

Wu C \& Alman B a 2008 Side population cells in human cancers. Cancer Letters 268 1-9. (doi:10.1016/j.canlet.2008.03.048)

Wu C, Wei Q, Utomo V, Nadesan P, Whetstone H, Kandel R, Wunder JS \& Alman B a 2007 Side population cells isolated from mesenchymal neoplasms have tumor initiating potential. Cancer Research 67 8216-8222. (doi:10.1158/0008-5472.CAN-07-0999)

Xu M, Shorts-Cary L, Knox AJ, Kleinsmidt-DeMasters B, Lillehei K \& Wierman ME 2009a Epidermal growth factor receptor pathway substrate 8 is overexpressed in human pituitary tumors: role in proliferation and survival. Endocrinology 150 2064-2071. (doi:10.1210/en.2008-1265)

Xu Q, Yuan X, Tunici P, Liu G, Fan X, Xu M, Hu J, Hwang JY, Farkas DL, Black KL et al. 2009b Isolation of tumour stem-like cells from benign tumours. British Journal of Cancer 101 303-311. (doi:10.1038/sj.bjc.6605142)

Yoon C-H, Kim M-J, Lee H, Kim R-K, Lim E-J, Yoo K-C, Lee G-H, Cui Y-H, Oh YS, Gye MC et al. 2012 PTTG1 oncogene promotes tumor malignancy via epithelial to mesenchymal transition and expansion of cancer stem cell population. The Journal of Biological Chemistry 287 1951619527. (doi:10.1074/jbc.M111.337428)

Yunoue S, Arita K, Kawano H, Uchida H, Tokimura H \& Hirano H 2011 Identification of CD133+ cells in pituitary adenomas. Neuroendocrinology 94 302-312. (doi:10.1159/000330625)

Zhu X, Gleiberman AS \& Rosenfeld MG 2007 Molecular physiology of pituitary development: signaling and transcriptional networks. Physiological Reviews 87 933-963. (doi:10.1152/physrev.00006.2006)

Zhu L, Gibson P, Currle DS, Tong Y, Richardson RJ, Bayazitov IT, Poppleton H, Zakharenko S, Ellison DW \& Gilbertson RJ 2009 Prominin 1 marks intestinal stem cells that are susceptible to neoplastic transformation. Nature 457: 603-607.

Zhu Z, Khan MA, Weiler M, Blaes J, Jestaedt L, Geibert M, Zou P, Gronych J, Bernhardt O, Korshunov A et al. 2014 Targeting Self-Renewal in High-Grade Brain Tumors Leads to Loss of Brain Tumor Stem Cells and Prolonged Survival. Cell Stem Cell 15 185-198. (doi:10.1016/j.stem.2014.04.007) 


\section{Page 43 of 65}

1036

$\mid+43$

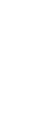

43

(1)

.

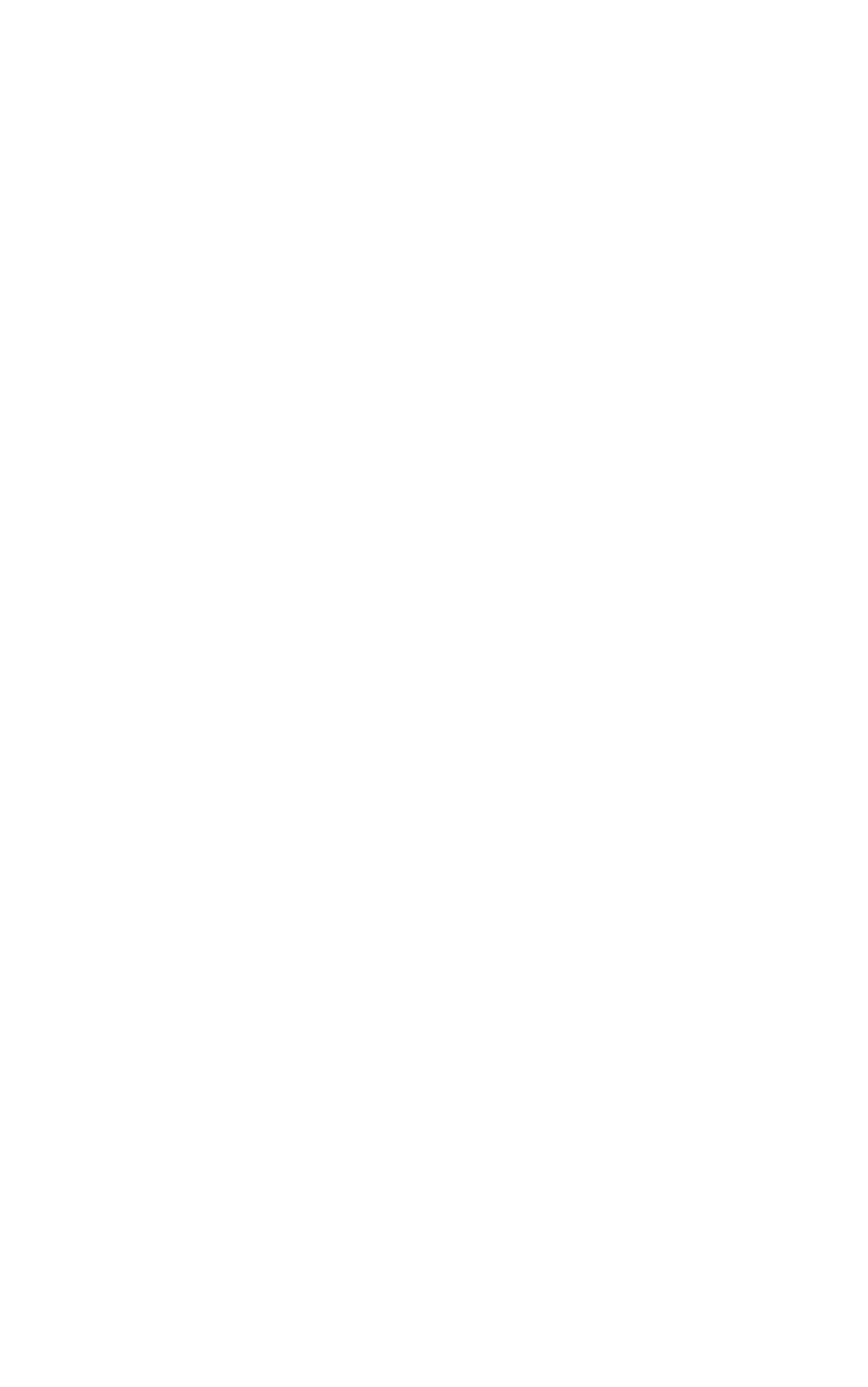

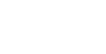




\section{FigURE LEGENDS}

Fig. 1. Identification and characterization of the side population (SP) in human pituitary adenomas

(A) Dot plots of dual-wavelength FACS analysis of human pituitary adenoma cells after incubation with Hoechst33342 alone (left), or together with verapamil (right). The SP (black) and MP (white) are gated and SP proportions are indicated. A representative example is shown.

(B) Boxplot of SP proportions obtained from NF-A $(n=33)$ and $\mathrm{GH}-\mathrm{A}(\mathrm{n}=20)$ as well as from all samples taken together $(\mathrm{n}=60)$. Minimum and maximum values (whiskers) and outliers (dots) are indicated.

(C) Dot plots of FACS analysis of human pituitary adenoma cells after incubation with

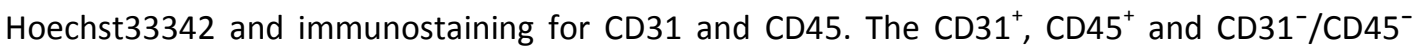
cells within the SP are also shown (inset).

(D) Percentage of $\mathrm{CD} 1^{+}$(upper panel) and $\mathrm{CD} 5^{+}$cells (lower panel) within the SP versus the SP proportion within the pituitary adenomas analyzed ( $n=37$ and 31 , respectively).

(E) Expression analysis by RT-qPCR of a selection of markers identified as differentially expressed in the pituitary adenoma $\mathrm{CD} 31^{\circ} / \mathrm{CD} 45^{\circ} \mathrm{SP}(\mathrm{pSP})$ versus the pMP by microarray analysis. Bars indicate mean of fold expression pSP/pMP \pm SEM ( $n=7$ pituitary adenomas); ${ }^{*}, p<0.05$.

Fig. 2. Human pituitary tumors contain sphere-forming cells segregating to the pSP

(A) Smooth-edged spheres (arrows) develop in cultures of total pituitary adenoma cells, clearly distinct from clumps of cells sticking together (arrowheads).

(B) Examples of spheres at higher magnification.

(C) Spheres (arrow) show Sox2 immunofluorescent signal (red) whereas clumps do not (arrowheads). Nuclei are stained with ToPro3. A representative example is shown (left: lightmicroscopic image; right: overlay).

(D) Secondary spheres (arrows) form after re-seeding the dissociated primary sphere cells. 
(E) Example of a secondary sphere at higher magnification.

(F) Third-generation spheres (arrow) develop after re-seeding the dissociated second-generation sphere cells.

(G) Spheres develop from pSP cells of pituitary adenoma, although their number is low. In pMP cell cultures, only clumps of cells are observed (inset).

All pictures were taken at 7 days of culture. Scale bar: $50 \mu \mathrm{m}$.

Fig. 3. Identification and characterization of the SP in the AtT20 pituitary tumor cell line

(A) Dot plots of dual-wavelength FACS analysis of AtT20 cells after incubation with Hoechst33342 alone (left), or together with verapamil (right). The SP (black) and MP (white) are gated and SP proportions are indicated. A representative example is shown.

(B) Cd44 and Cxcr4 gene expression in the SP and MP of AtT20 cells in culture, as determined by RT-qPCR. Bars show mean of fold SP/MP \pm SEM $(n=3) ; *, p<0.05$.

(C) Volume of xenograft tumors grown in SCID mice as measured at day 40 (d40) and d47 after sc injection of the indicated number of AtT20 SP cells (black) and MP cells (grey). Bars show mean \pm SEM $(5$ mice for 10000 cells, and 4 mice for 5000 and 1000 cells; injected in 2 or 3 independent experiments; see Supplementary Fig. S5B); *, p<0.05.

Fig. 4. Involvement of the TGF $\beta$ and Cxcr4 pathways in EMT-/TSC-associated properties of the AtT20 pituitary tumor cell line

(A) Gene expression in TGF $\beta 1$-treated (72 hr) and -untreated AtT20 cells as determined by RT-qPCR. Bars show mean of fold TGF $\beta 1 /$ control $\pm \operatorname{SEM}(n=3) ;{ }^{*}, p<0.05$.

(B) Effect of TGF $\beta 1$ and AMD3100 on the motility of AtT20 cells. Light-microscopic pictures of the AtT20 cell culture after applying a scratch 'wound', treated or not (control) with TGF $\beta 1$ or AMD3100 for the indicated time period. Representative examples are shown. Scale bar: $100 \mu \mathrm{m}$. The $\%$ open 
area' was determined with TScratch software in the cultures without compound (black), or with TGF $\beta 1$ (grey) or AMD3100 (dark grey). Bars show mean \pm SEM $(n=4) ;{ }^{*}, p<0.05$.

(C) Effect of the Cxcr4-antagonist AMD3100 on AtT20 tumor growth. Immunodeficient SCID mice with growing AtT20-derived sc tumors were treated with intratumoral injections of AMD3100 (grey) or vehicle (PBS; black) starting from day 21 (arrow) after sc AtT20 cell implantation. Volumes of individual tumors are shown, with horizontal line indicating the mean of each group at each time point ( $n=3$, with an initial number of 5 mice per independent experiment, a number declining towards $\mathrm{d} 35-42$ because of gradual decease of mice); ${ }^{*}, \mathrm{p}<0.05$.

(D) Gene expression in AMD3100-treated (20 days) and -untreated AtT20 xenograft tumors as determined by RT-qPCR. Bars show mean of fold AMD3100/control \pm SEM ( $n=3$ except for Snai1 and Snai2 where $\mathrm{n}=2) ;{ }^{*}, \mathrm{p}<0.05$.

(E) Effect of AMD3100 on AtT20 cell viability. Percentage of dying/dead AtT20 cells (as determined by trypan blue exclusion) after treatment with AMD3100 (grey) or vehicle (black). Bars show mean $\pm \operatorname{SEM}(n=3) ;{ }^{*}, p<0.05$.

(F) Effect of AMD3100 on AtT20 cell apoptosis. Percentage of TUNEL ${ }^{+}$cells after treatment with AMD3100 (grey) or vehicle (black). Bars show mean \pm SEM $(n=3) ;{ }^{*}, p<0.05$.

(G) Effect of AMD3100 on AtT20 cell proliferation. Percentage of Ki67 ${ }^{+}$AtT20 cells after treatment with AMD3100 (grey) or vehicle (black). Bars show mean $\pm \operatorname{SEM~}(n=3) ;{ }^{*}, p<0.05$.

\section{Fig. 5. Pituitary stem cells in the $\operatorname{Drd2}^{-/}$pituitary tumor model}

(A) Fold difference in absolute number of pSP cells in the anterior pituitary (AP) of homozygous $\operatorname{Drd2}^{-/}(\mathrm{n}=5)$ and heterozygous $\operatorname{Drd} 2^{+/-}$mice $(\mathrm{n}=2)$, relative to wildtype $\operatorname{Drd2^{+/+}}$ mice (set as 1$) .{ }^{*}$, $\mathrm{p}<0.05$ versus $\mathrm{Drd} 2^{+/+}$mice.

(B) Absolute number of Sox $2^{+}$cells in the AP of homozygous $\operatorname{Drd} 2^{--}$, heterozygous $\mathrm{Drd2}^{+/-}$mice and wildtype $\operatorname{Drd2}^{+/+}$mice. Bars represent mean $\pm \operatorname{SEM}(n=3)$, with indication of the nuclear-Sox $2^{+}$cells 
(black segment) and the cytoplasmic-Sox $2^{+}$cells (grey segment). ${ }^{*}, \mathrm{p}<0.05$ versus $D r d 2^{+/+}$mice (for total Sox $2^{+}$cell number).

(C) Immunofluorescent staining of dissociated AP cells (cytospins) from wildtype $\mathrm{Drd} 2^{+/+}$mice (upper panel) and homozygous Drd2 ${ }^{-/}$mice (middle and lower panels) for Sox2 (red) and Ki67 (green). Double Sox $2^{+} / \mathrm{Ki}^{+} 7^{+}$cells are indicated (arrows). Nuclei are stained with DAPI. Representative examples are shown (female mice, 10-12 months of age). Scale bar: 50 $\mathrm{mm}$.

(D) Confocal images of pituitary vibratome sections of $\mathrm{Drd2}^{-/}, \mathrm{Drd2}^{+/-}$and wildtype $\mathrm{Drd2}^{+/+}$mice immunofluorescently stained for Sox2 (red) and prolactin (PRL, green). Representative examples are shown (female mice, 10-13 months of age). In all mouse phenotypes, Sox $2^{+}$cells are found in the marginal cell layer along the cleft. In $\operatorname{Drd} 2^{-}$pituitary Sox $2^{+}$cells clustered in small groups are often observed within the $\mathrm{PRL}^{+}$tumor cell mass (arrows), but clusters of Sox $2^{+}$cells are also found scattered in the anterior pituitary (AP) parenchyma of control $\mathrm{Drd2}^{+/}$and $\mathrm{Drd2}^{+/+}$mice.

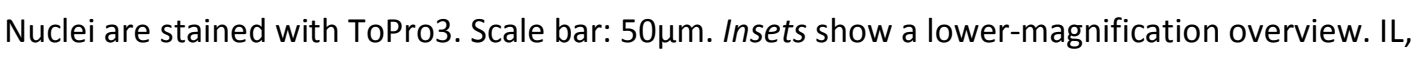
intermediate lobe.

\section{SUPPLEMENTARY FigURE LEGENDS}

\section{Fig. S1. Characterization of the side population (SP) in human pituitary adenomas}

(A) Boxplot of SP proportions measured in pituitary adenoma samples immediately after surgical resection (Fresh; $\mathrm{n}=24$ ) or after cryopreservation and thawing (Frozen; $\mathrm{n}=36$ ). Minimum and maximum values (whiskers) and outliers (dots) are indicated.

(B) Forward scatter (FSC) and side scatter (SSC) of the adenoma SP cells (blue) compared to the MP cells (orange), both as gated in Fig. $1 \mathrm{~A}$.

(C) Principal Component analysis (PCA) of whole-genome expression data. A graphic is provided illustrating the distribution of the 9 micro-arrayed SPs (grey) and MPs (black) of pituitary adenomas along 2 principal components (as defined by Agilent's Feature Extraction Software). 
(D) Hierarchical clustering of whole-genome expression data. Upper panel: schematic representation of gene expression levels in adenoma SP versus MP and resultant hierarchical clustering, using the probe sets (2760) identified as differentially expressed in the less stringent protocol (see Materials and Methods). Lower panel: schematic representation of gene expression levels in adenoma SP versus MP and resultant hierarchical clustering, using the probe sets (334) identified as differentially expressed in the more stringent approach (see Materials and Methods). Expression levels are indicated on a continuous color scale from downregulated (green) to upregulated (red) in the SP versus the MP. The SP samples are indicated by grey dots and the MP samples by black dots, as shown under each heat map.

Fig. S2. Genes differentially expressed between $\mathrm{CD}^{-} / \mathrm{CD}^{-} \mathrm{SP}(\mathrm{pSP})$ and $\mathrm{CD} 31^{-} / \mathrm{CD}^{-} 5^{-} \mathrm{MP}$ (pMP) from human pituitary adenomas

(A) Volcano plot ( $\log _{2}$-ratio versus minus $\log _{10} \mathrm{p}$-value) of whole-genome expression data from the pSP and pMP of human pituitary adenomas $(n=5)$. Statistically upregulated genes (cut-off: fold-change $\geq 2$ and uncorrected $\mathrm{p}<0.001$; see Materials and Methods) are indicated in red, downregulated genes in green. It should be noted that many genes are scored altered by the fold-change criteria but not statistically significant because of the still relatively small number of samples analyzed.

(B) MA plot (average intensity versus $\log _{2}$-ratio) of whole-genome expression data from the pSP and pMP of human pituitary adenomas $(n=5)$. Statistically upregulated genes as determined in the Volcano plot are indicated in red, downregulated genes in green.

(C) Name of the microarray probes statistically upregulated (left; red) or downregulated (right; green) in the PSP versus PMP, as extracted from the Volcano plot.

(D) Immunohistochemical analysis of E-cadherin, vimentin, IL-6 and NOTCH2 in paraffinembedded pituitary adenoma sections. Immunostaining for E-cadherin shows several immunonegative patches. Vimentin, IL-6 and NOTCH2 are found in some tumor cells (arrows), 
either alone or in clusters. Vimentin is also present in pericapillar cells (arrowheads). Scale bar: $50 \mu \mathrm{m}$.

Fig. S3. Expression of stemness markers in spheres from human pituitary tumors

(A-B) Immunofluorescent analysis of spheres from human pituitary adenomas at day 7 of culture for SOX2 (red; A) or nestin (green; B). Nuclei are stained with ToPro3. Representative examples are shown (left: light-microscopic image; right: overlay).

(C) Immunofluorescent analysis of spheres from a human GH-A at day 8 of culture for SOX2 (red; A) and GH (green; B). Some sphere cells express the hormone produced by the original tumor (here, GH).

Scale bar: $50 \mu \mathrm{m}$.

\section{Fig. S4. Pituitary adenoma after transplantation under the kidney capsule}

(A) H\&E staining 6 months after transplantation of pituitary adenoma fragments under the kidney capsule of an immunodeficient SCID mouse, showing renal tissue (pink) and viable tumor tissue (arrows).

(B) Enlargement of the boxed area in A, showing the pituitary adenoma structure.

Scale bar: $50 \mu \mathrm{m}$.

\section{Fig. S5. Tumor growth from AtT20 and effect of TGF $\beta 1$}

(A) AtT20 cells $\left(5 \times 10^{5}\right)$ were sc injected into SCID mice. Individual tumor volumes are shown, with horizontal line indicating the mean of each group at each time point $(n=2$, with an initial number of 4 mice per independent experiment).

(B) AtT20 SP (black) and MP (grey) were sc injected into SCID mice at the indicated number of cells $(10000,5000$ or 1000$)$. Individual tumor volumes are shown, with horizontal line indicating the mean of each group at each time point ( $n=5$ mice for 10000 cells, $n=4$ mice for 5000 and 
1000 cells; injected in 2 or 3 independent experiments); ${ }^{*}, p<0.05$. Some examples of dissected xenograft tumors are shown.

(C) AtT20 cells were pretreated with TGF $\beta 1$ or vehicle for $72 \mathrm{hr}$ and then sc implanted in SCID mice. Individual tumor volumes are shown, with horizontal line indicating the mean of each group at each time point ( $n=3$, with an initial number of 5 mice per independent experiment).

Fig. S6. Expression of the pituitary stem cell marker Sox2 in pituitary tumor cell lines

(A) Sox2 gene expression in the SP and MP from the AtT20 cell line and from the rat lactosomatotrope GH3 cell line as determined by RT-qPCR. Bars show mean fold SP/MP \pm SEM $(n=3) ;{ }^{*}, p<0.05$.

(B) Dot plots of dual-wavelength FACS analysis of the GH3 cell line after incubation with Hoechst33342 alone (left), or together with verapamil (right). The SP (black) and MP (white) are gated and SP proportions are indicated. A representative example is shown. 


\section{Fig. S7. Pituitary stem cells in the $\mathrm{Drd2}^{-{ }^{--}}$pituitary tumor model}

(A) Transversal MRI pictures of the head of a female heterozygous Drd2 $2^{+/}$(upper left panel) and homozygous Drd2 ${ }^{-/}$(lower left panel) mouse at 8 months of age. The boxed region shows the pituitary, clearly bigger in the $\operatorname{Drd} 2^{-/}$mouse. Photographs of the pituitary in situ after euthanasia and removal of the brain in a heterozygous $\mathrm{Drd2}^{+-}$(upper row) and homozygous $\operatorname{Drd}^{-/}$(lower row) mouse at 14 months of age. The pituitary of the $\mathrm{Drd}^{-/}$mouse is clearly bigger and contains large tumorous nodules. Scale bar: $1 \mathrm{~mm}$.

(B) Dot plots of dual-wavelength FACS analysis of $\operatorname{Drd}^{-/}$anterior pituitary (AP) after incubation with Hoechst33342 alone (left) or together with verapamil (right), and immunostained for CD31 and CD45. The SP (black) and MP (white) are gated and SP proportions are indicated. CD45 $\mathrm{CD}^{+} 1^{+}$and $\mathrm{CD} 31^{-} / \mathrm{CD} 45^{-}$cells within the SP are shown (inset). A representative example is given.

(C) Phase-contrast pictures of representative colonies formed after 4 days from $\mathrm{Drd}^{-\%}$ and Drd2 ${ }^{+/}$AP cells. Scale bar: $100 \mu \mathrm{m}$.

(D) Additional pictures of Sox2 (red) and PRL (green) immunofluorescent staining in vibratome $\left(A^{\prime}-E^{\prime}\right)$ and paraffin-embedded $\left(F^{\prime}\right.$ and $\left.G^{\prime}\right)$ sections of $\operatorname{Drd2}^{-\%}, \operatorname{Drd2}^{+/}$and wildtype $\operatorname{Drd2}^{+/+}$ pituitaries (female mice, 10-13 months of age). In all mouse phenotypes, Sox $2^{+}$cells are found in the marginal cell layer along the cleft. In $D r d 2^{--}$pituitary, Sox $2^{+}$cells clustered in groups are often observed within the $\mathrm{PRL}^{+}$tumor cell mass $\left(\mathrm{B}^{\prime}\right.$, arrows). Clusters are sometimes large in size ( $\mathrm{F}^{\prime}$ with blow-up in $\mathrm{G}^{\prime}$ ). Cytoplasmic-Sox $2^{+}$cells are more abundant in $\mathrm{Drd}^{-\%}$ than control pituitaries (arrowheads).

Nuclei were stained with ToPro3 $\left(A^{\prime}-E^{\prime}\right)$ or DAPI $\left(F^{\prime}\right.$ and $\left.G^{\prime}\right)$. Scale bar: $50 \mu m$. Insets show a lower-magnification overview. AP, anterior pituitary; IL, intermediate lobe. 
Table 1. Summary of clinical and experimental data of the pituitary adenoma samples analyzed

\begin{tabular}{|c|c|c|c|c|c|c|c|c|c|c|c|}
\hline $\begin{array}{l}\text { Pituitary Adenoma } \\
\text { (PA) sample } \\
\text { number }\end{array}$ & Gender & $\begin{array}{c}\text { Age at } \\
\text { time of } \\
\text { surgery } \\
(y r)\end{array}$ & $\begin{array}{c}\text { PA } \\
\text { phenotype }^{a}\end{array}$ & $\operatorname{Size}^{\mathrm{b}}$ & $\begin{array}{c}\text { Fresh or } \\
\text { cryopreserved }\end{array}$ & $\begin{array}{c}\text { SP } \\
\text { (\% of total cells) }\end{array}$ & $\begin{array}{c}\mathrm{CD}^{+} 1^{+} \\
(\% \text { of SP) }\end{array}$ & $\begin{array}{c}\mathrm{CD}^{+} 5^{+} \\
(\% \text { of SP) }\end{array}$ & Micro-array & $\begin{array}{c}\text { RT- } \\
\text { qPCR }\end{array}$ & $\mathrm{IHH}$ \\
\hline PA 01 & $M$ & 62 & NF-A & Macro & $\mathrm{F}$ & 7.5 & ND & ND & & & \\
\hline PA 02 & $M$ & 41 & NF-A & Macro & $\mathrm{F}$ & 1.5 & ND & ND & & & \\
\hline PA 04 & $M$ & 37 & GH-A & Macro & $\mathrm{F}$ & 1.4 & ND & ND & & & \\
\hline PA 05 & $\mathrm{~F}$ & 28 & GH-A & Macro & $\mathrm{F}$ & 1.8 & ND & ND & & & \\
\hline PA 06 & $M$ & 84 & GH-A & Macro & $F$ & 1.4 & ND & ND & $x$ & & \\
\hline PA 07 & $\mathrm{~F}$ & 76 & GH-A & Macro & $\mathrm{F}$ & 1.6 & ND & ND & $x$ & & \\
\hline PA 08 & $M$ & 39 & NF-A & Micro & $\mathrm{F}$ & 2.0 & ND & ND & & & \\
\hline PA 11 & $\mathrm{~F}$ & 59 & GH-A & Macro & C & 8.0 & ND & ND & & & \\
\hline PA 12 & $M$ & 71 & GH-A & Macro & C & 1.8 & ND & ND & & & \\
\hline PA 13 & $\mathrm{~F}$ & 44 & ACTH-A & Micro & $\mathrm{F}$ & 0.5 & ND & ND & & & \\
\hline PA 14 & $\mathrm{~F}$ & 72 & NF-A & Macro & C & 1.2 & ND & ND & & & \\
\hline PA 15 & $M$ & 79 & NF-A & Macro & $\mathrm{C}$ & 1.4 & ND & ND & & & \\
\hline PA 16 & $M$ & 72 & GH-A & Micro & C & 0.7 & ND & ND & & & \\
\hline PA 17 & $M$ & 35 & NF-A & Macro & C & 0.5 & ND & ND & $x$ & & \\
\hline
\end{tabular}




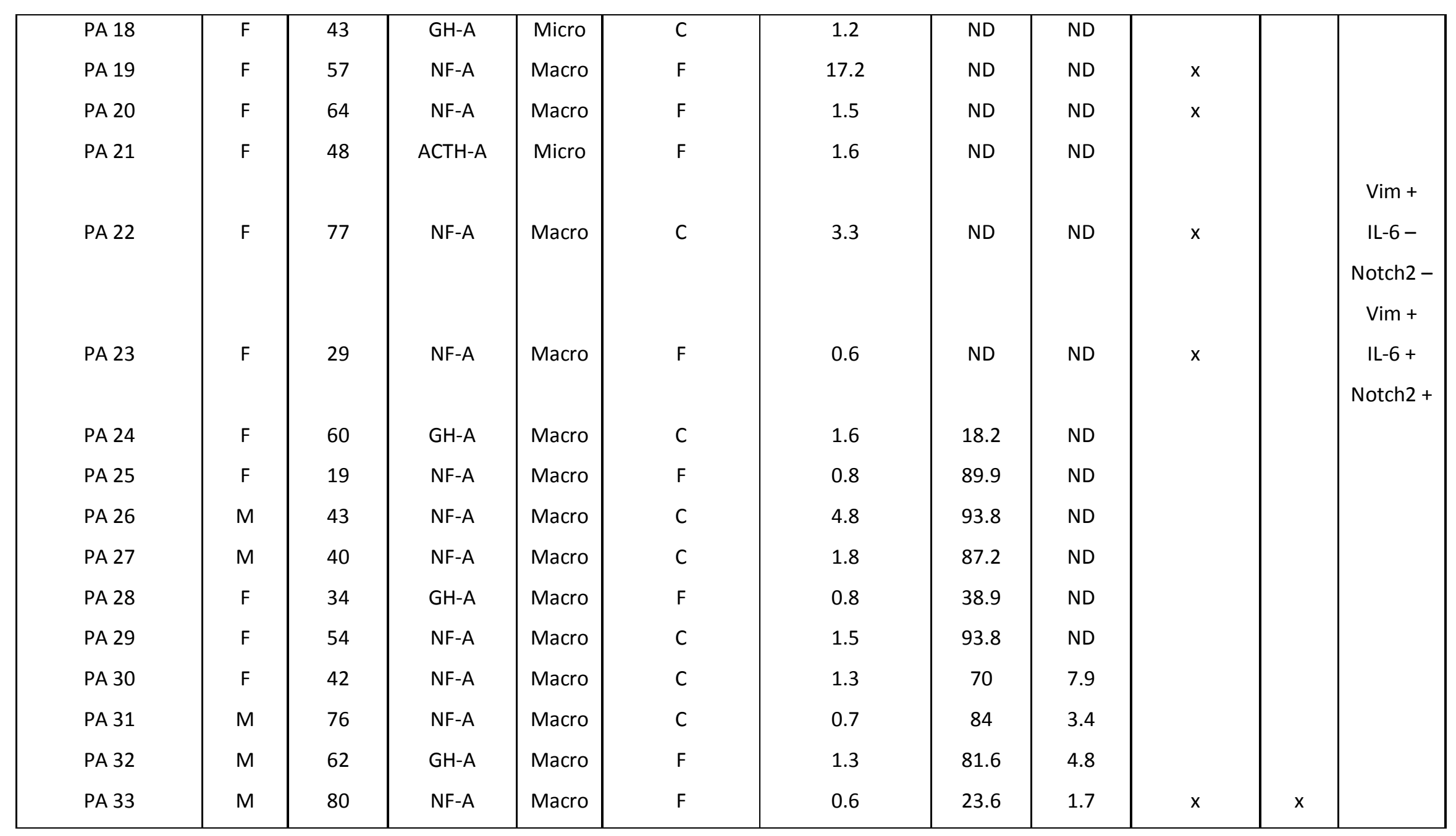




\begin{tabular}{|c|c|c|c|c|c|c|c|c|c|c|c|}
\hline PA 34 & $M$ & 70 & NF-A & Macro & $F$ & 1.3 & 24 & 27.3 & $x$ & $x$ & $\begin{array}{c}\text { Vim + } \\
\text { IL-6- } \\
\text { Notch2 + }\end{array}$ \\
\hline PA 35 & $M$ & 40 & NF-A & Macro & $C$ & 1.5 & 18.7 & 11.6 & $x$ & $x$ & $\begin{array}{c}\text { Vim - } \\
\text { IL-6 - } \\
\text { Notch2 - }\end{array}$ \\
\hline PA 36 & $M$ & 62 & NF-A & Macro & $C$ & 0.6 & 71.6 & 17.8 & & & \\
\hline PA 37 & $\mathrm{~F}$ & 50 & $\mathrm{GH}-\mathrm{A}$ & Micro & $C$ & 1.8 & 57.5 & 6.7 & & & \\
\hline PA 38 & $M$ & 70 & NF-A & Macro & $C$ & 0.6 & 60.9 & 3.9 & $x$ & $x$ & $\begin{array}{c}\text { IL-6 + } \\
\text { Notch2 + }\end{array}$ \\
\hline PA 39 & $F$ & 39 & PRL-A & Macro & C & 1.2 & 43.3 & 33.5 & & & Vim + \\
\hline PA 40 & $M$ & 63 & NF-A & Macro & $F$ & 1.1 & 12.6 & 66.6 & $x$ & $x$ & $\begin{array}{c}\text { IL-6 + } \\
\text { Notch2 + }\end{array}$ \\
\hline PA 41 & $M$ & 39 & NF-A & Macro & $F$ & 0.9 & 22 & 3.9 & & & \\
\hline PA 42 & $\mathrm{~F}$ & 30 & NF-A & Macro & C & 0.5 & 13 & 40.4 & & & \\
\hline PA 43 & $M$ & 61 & $\mathrm{GH}-\mathrm{A}$ & Macro & $C$ & 6.8 & 95.2 & 1.3 & & & \\
\hline PA 44 & $M$ & 49 & NF-A & Macro & $F$ & 0.6 & 33 & 35 & & $x$ & \\
\hline PA 45 & $M$ & 63 & NF-A & Macro & $F$ & 2.4 & 60 & 4 & & & \\
\hline PA 46 & $\mathrm{~F}$ & 27 & GH-A & Macro & C & 0.6 & 23 & 33.5 & & $x$ & \\
\hline
\end{tabular}




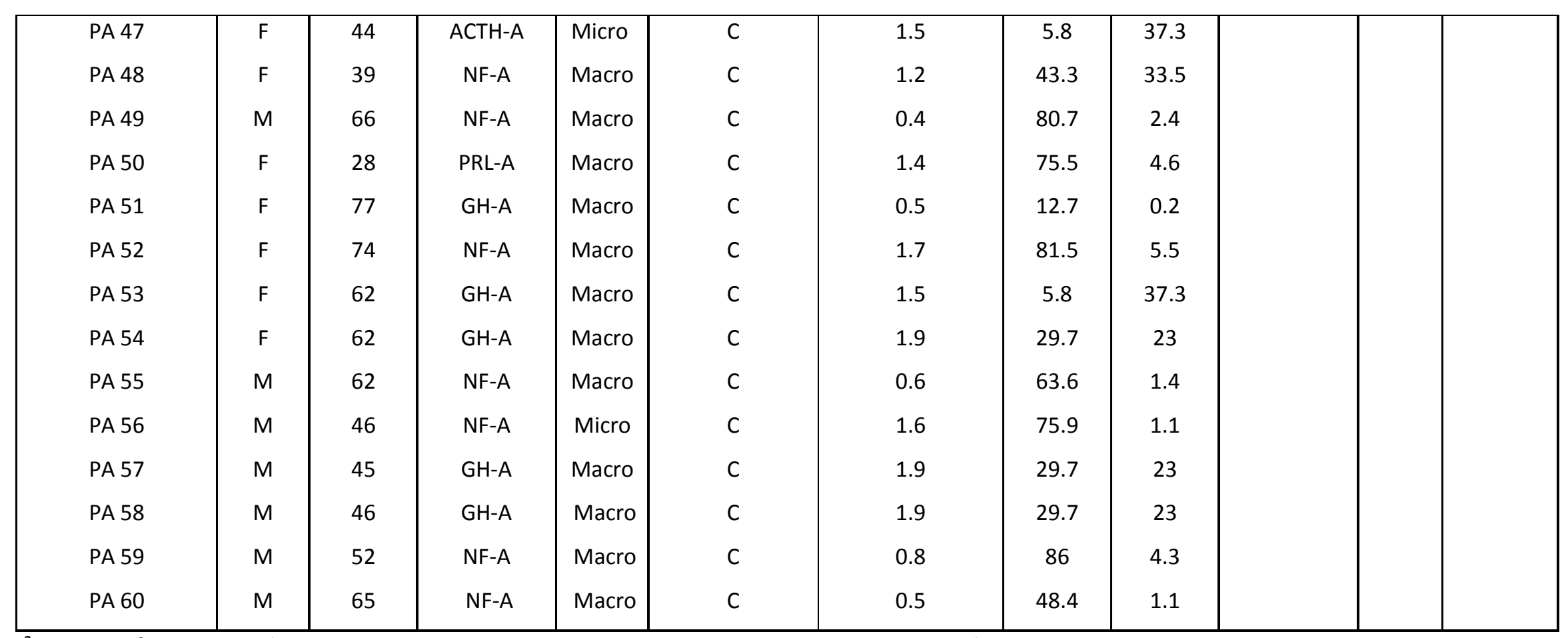

${ }^{a} \mathrm{NF}-\mathrm{A}$, non-functioning adenoma; GH-A, somatotropinoma, ACTH-A, corticotropinoma; PRL-A, prolactinoma.

${ }^{b}$ Size: micro-adenoma: $<1 \mathrm{~cm}$ (micro); macro-adenoma: $\geq 1 \mathrm{~cm}$ (macro).

$\mathrm{ND}$, not determined; $\mathrm{IHH}$, immunohistochemistry. 
Table 2. Expression of a selection of genes in the total SP of human pituitary adenoma as concluded from microarray analysis

\begin{tabular}{|c|c|c|}
\hline Gene $^{a}$ & Gene description & Expression in $\mathbf{S P}^{b}$ \\
\hline \multicolumn{3}{|l|}{ (Tumor) stemness } \\
\hline$A B C B 1(M D R / T A P)$ & ATP-binding cassette, sub-family $B$, member 1 & \\
\hline$A B C G 2(B C R P 1)$ & ATP-binding cassette, sub-family G (WHITE), member 2 & \\
\hline$C D 44$ & CD44 molecule (Indian bloud group) & \\
\hline CXCR4 & Chemokine (C-X-C motif) receptor 4 & \\
\hline KIT & v-kit Hardy-Zuckerman 4 feline sarcoma viral oncogene homolog & \\
\hline KLF4 & Kruppel-like factor 4 (gut) & \\
\hline NES & Nestin & \\
\hline \multicolumn{3}{|l|}{$\begin{array}{l}\text { Notch pathway } \\
\text { (and related) }\end{array}$} \\
\hline DLL1 & Delta-like 1 (Drosophila) & \\
\hline DLL3 & Delta-like 3 (Drosophila) & \\
\hline DLL4 & Delta-like 4 (Drosophila) & \\
\hline HES1 & Hairy and enhancer of split 1 (Drosophila) & \\
\hline HES2 & Hairy and enhancer of split 2 (Drosophila) & \\
\hline HES5 & Hairy and enhancer of split 5 (Drosophila) & \\
\hline HEYL & Hairy/enhancer-of-split related with YRPW motif-like & \\
\hline$J A G 1$ & Jagged 1 & \\
\hline NOTCH1 & Notch 1 & \\
\hline NOTCH2 & Notch 2 & \\
\hline NOTCH4 & Notch 4 & \\
\hline \multicolumn{3}{|l|}{$\begin{array}{c}\text { TGF } \beta / B M P \\
\text { pathway } \\
\text { (and related) }\end{array}$} \\
\hline$B M P 2$ & Bone morphogenetic protein 2 & \\
\hline$B M P 4$ & Bone morphogenetic protein 4 & \\
\hline BMP6 & Bone morphogenetic protein 6 & \\
\hline MEN1 & Multiple endocrine neoplasia 1 & \\
\hline SMAD2 & SMAD family member 2 & \\
\hline SMAD3 & SMAD family member 3 & \\
\hline
\end{tabular}




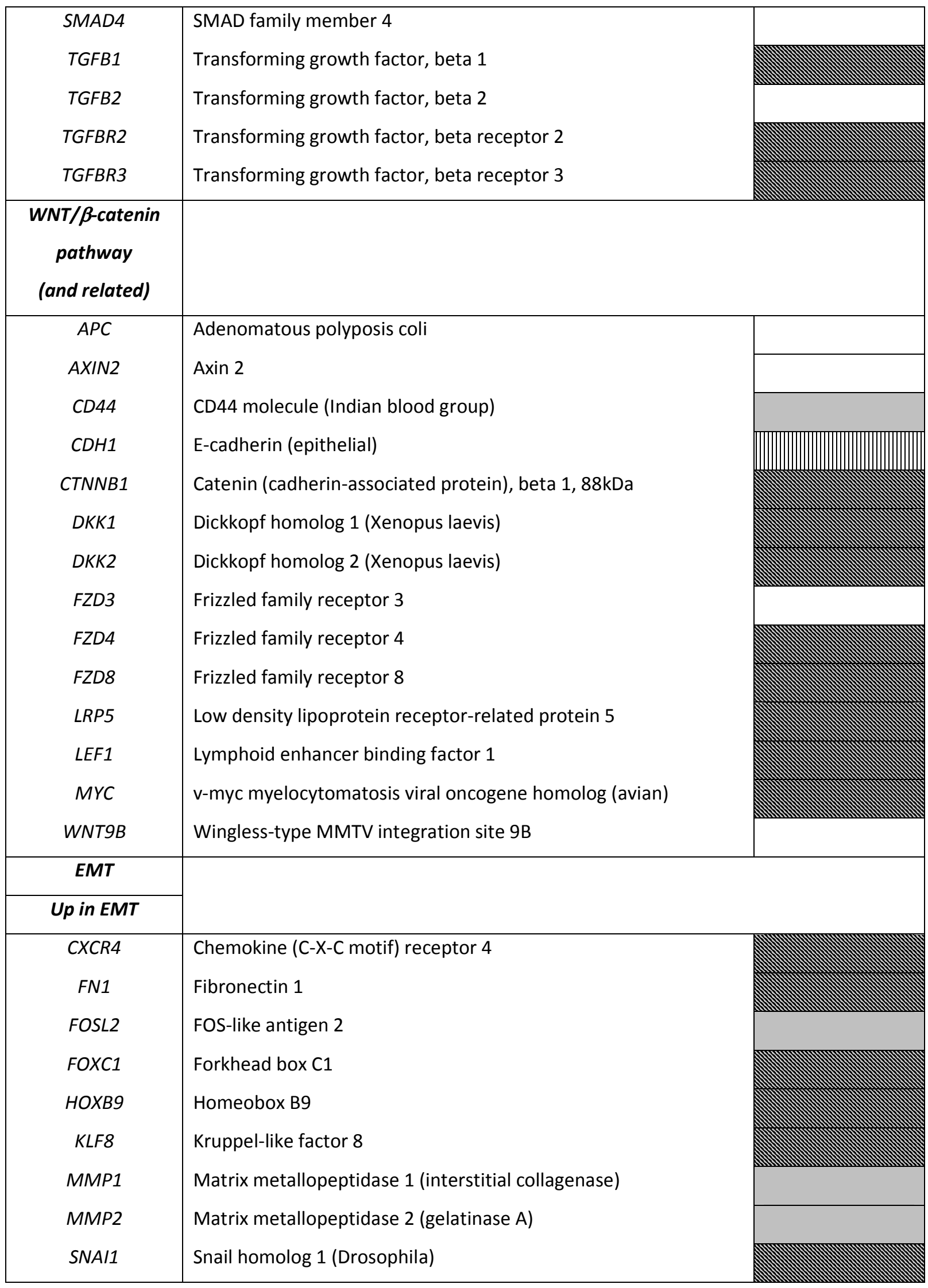




\begin{tabular}{|c|c|}
\hline TCF4 & Transcription factor 4 \\
\hline VIM & Vimentin \\
\hline ZEB1 & Zinc finger E-box binding homeobox 1 \\
\hline ZEB2 & Zinc finger E-box binding homeobox 2 \\
\hline \multicolumn{2}{|l|}{ Down in EMT } \\
\hline $\mathrm{CDH} 1$ & E-cadherin (epithelial) \\
\hline CLDN1 & Claudin 1 \\
\hline \multicolumn{2}{|l|}{ Angiogenesis/ } \\
\hline $\mathrm{CDH} 5$ & Cadherin 5, type 2 (vascular endothelium), VE-cadherin \\
\hline$F L K 1 / K D R$ & Kinase insert domain receptor (a type III receptor tyrosine kinase) \\
\hline PECAM1 (CD31) & Platelet/endothelial cell adhesion molecule \\
\hline TEK/TIE2 & Tyrosine kinase, endothelial \\
\hline TIE1 & Tyrosine kinase with immunoglobulin-like and EGF-like domains 1 \\
\hline VCAM1 & Vascular cell adhesion molecule 1 \\
\hline VWF & von Willebrand factor \\
\hline \multicolumn{2}{|l|}{ Immune/ } \\
\hline \multicolumn{2}{|l|}{ hematopoietic } \\
\hline CD45/PTPRC & Protein tyrosine phosphatase, receptor type C \\
\hline
\end{tabular}

${ }^{a}$ Selection of genes as analyzed by microarray; genes are listed alphabetically per group.

${ }^{b}$ Expression level of the gene in the total adenoma SP: (W) when $>1.5$-fold upregulated in the SP versus the MP in at least $2 / 3^{\text {rd }}$ of the adenoma samples analyzed ( 6 or more out of the 9 ); $(\square)$ when $>1.5$-fold upregulated in the SP versus the MP in 5 out of the 9 adenoma samples; (Wس) when >1.5fold downregulated in the SP versus the MP of at least 6 out of the 9 adenoma samples analyzed. Indicated as $(\square)$ when $<1.5$-fold difference versus MP. 
Table 3. Expression of a selection of genes in the pSP of human pituitary adenoma as concluded from microarray analysis

\begin{tabular}{|c|c|c|}
\hline Gene $^{a}$ & Gene description & $\begin{array}{c}\text { Expression in } \\
\qquad S P^{b}\end{array}$ \\
\hline \multicolumn{3}{|l|}{$\begin{array}{l}\text { (Tumor) } \\
\text { stemness }\end{array}$} \\
\hline$A B C G 2(B C R P 1)$ & ATP-binding cassette, sub-family G (WHITE), member 2 & \\
\hline CD34 & CD34 molecule & \\
\hline CD44 & CD44 molecule & \\
\hline CXCR4 & Chemokine (C-X-C motif) receptor 4 & \\
\hline KIT & v-kit Hardy-Zuckerman 4 feline sarcoma viral oncogene homolog & \\
\hline LIFR & Leukemia inhibitory factor receptor & \\
\hline NES* & Nestin & \\
\hline \multicolumn{3}{|l|}{$\begin{array}{l}\text { Notch pathway } \\
\text { (and related) }\end{array}$} \\
\hline$D L K 1^{*}$ & Delta-like 1 homolog & \\
\hline$D L L 1^{*}$ & Delta-like 1 & \\
\hline DLL3* & Delta-like 3 & \\
\hline DLL4* & Delta-like 4 & \\
\hline HES $1^{*}$ & Hairy and enhancer of split1 & \\
\hline$H E Y 2^{*}$ & Hairy/enhancer-of-split related with YRPW motif 2 & \\
\hline$J A G 1^{*}$ & Jagged1 & \\
\hline$J A G 2^{*}$ & Jagged 2 & \\
\hline NOTCH1* & Notch gene homolog 1 & \\
\hline NOTCH2 & Notch gene homolog 2 & \\
\hline NOTCH4* & Notch gene homolog 4 & \\
\hline \multicolumn{3}{|l|}{$\begin{array}{c}\text { TGF6/BMP } \\
\text { pathway } \\
\text { (and related) }\end{array}$} \\
\hline$B M P 2$ & Bone morphogenetic protein 2 & \\
\hline$B M P R 2$ & Bone morphogenetic protein receptor 2 & \\
\hline TGFB2 & Transforming growth factor, beta 2 & \\
\hline TGFB1* & Transforming growth factor, beta 1 & \\
\hline$T G F B I$ & Transcription factor, beta-induced & \\
\hline
\end{tabular}




\begin{tabular}{|c|c|}
\hline TGFBR2 & Transforming growth factor, beta receptor II \\
\hline \multicolumn{2}{|l|}{$\begin{array}{c}\text { WNT/ } \beta \text {-catenin } \\
\text { pathway } \\
\text { (and related) }\end{array}$} \\
\hline$D K K 1^{*}$ & Dickkopf homolog 1 \\
\hline$D K K 2 *$ & Dickkopf homolog 2 \\
\hline$D K K 3$ & Dickkopf homolog 3 \\
\hline DKK4 & Dickkopf homolog 4 \\
\hline$F Z D 1^{*}$ & Frizzled 1 homolog \\
\hline FZD10 & Frizzled 10 homolog \\
\hline TCF3* & Transcription factor 3 \\
\hline TCF7L1 & Transcription factor 7-like 1 \\
\hline TCF7L2 & Transcription factor 7-like 2 \\
\hline WNT5a* & Wingless-related MMTV integration site $5 \mathrm{~A}$ \\
\hline \multicolumn{2}{|l|}{ EMT } \\
\hline CXCR4 & Chemokine (C-X-C motif) receptor 4 \\
\hline FN1 & Fibronectin \\
\hline SNAI1* & SNAIL homolog 1 \\
\hline SNAI2 (SLUG)* & SNAIL homolog 2 \\
\hline VIM & Vimentin \\
\hline ZEB1* & Zinc finger E-box binding homeobox 1 \\
\hline ZEB2 & Zinc finger E-box binding homeobox 2 \\
\hline \multicolumn{2}{|l|}{$\begin{array}{c}\text { Angiogenesis/ } \\
\text { endothelial }\end{array}$} \\
\hline VCAM1 & Vascular cell adhesion molecule 1 \\
\hline$V W F$ & von Willebrand factor \\
\hline
\end{tabular}

${ }^{a}$ Selection of genes as analyzed by microarray; genes are listed alphabetically per group

${ }^{b}$ Expression level of the gene in the adenoma CD31 ${ }^{-} / \mathrm{CD}^{-} 5^{-} \mathrm{SP}(\mathrm{pSP})$ : (W) when >1.5-fold upregulated in PSP versus PMP in all 5 of the adenoma samples; $(\square)$ in 4 out of the 5 tumors;

$(\square)$ in 3 out of the 5 tumors; (四) in 2 out of the 5 tumors; ( $\mathbf{\square}$ ) when >1.5-fold downregulated in at least 3 of the 5 tumors. Indicated as $(\square)$ when $<1.5$-fold difference versus MP.

* means $>1.5$-fold upregulation but $p>0.05$. 
Fig. 2
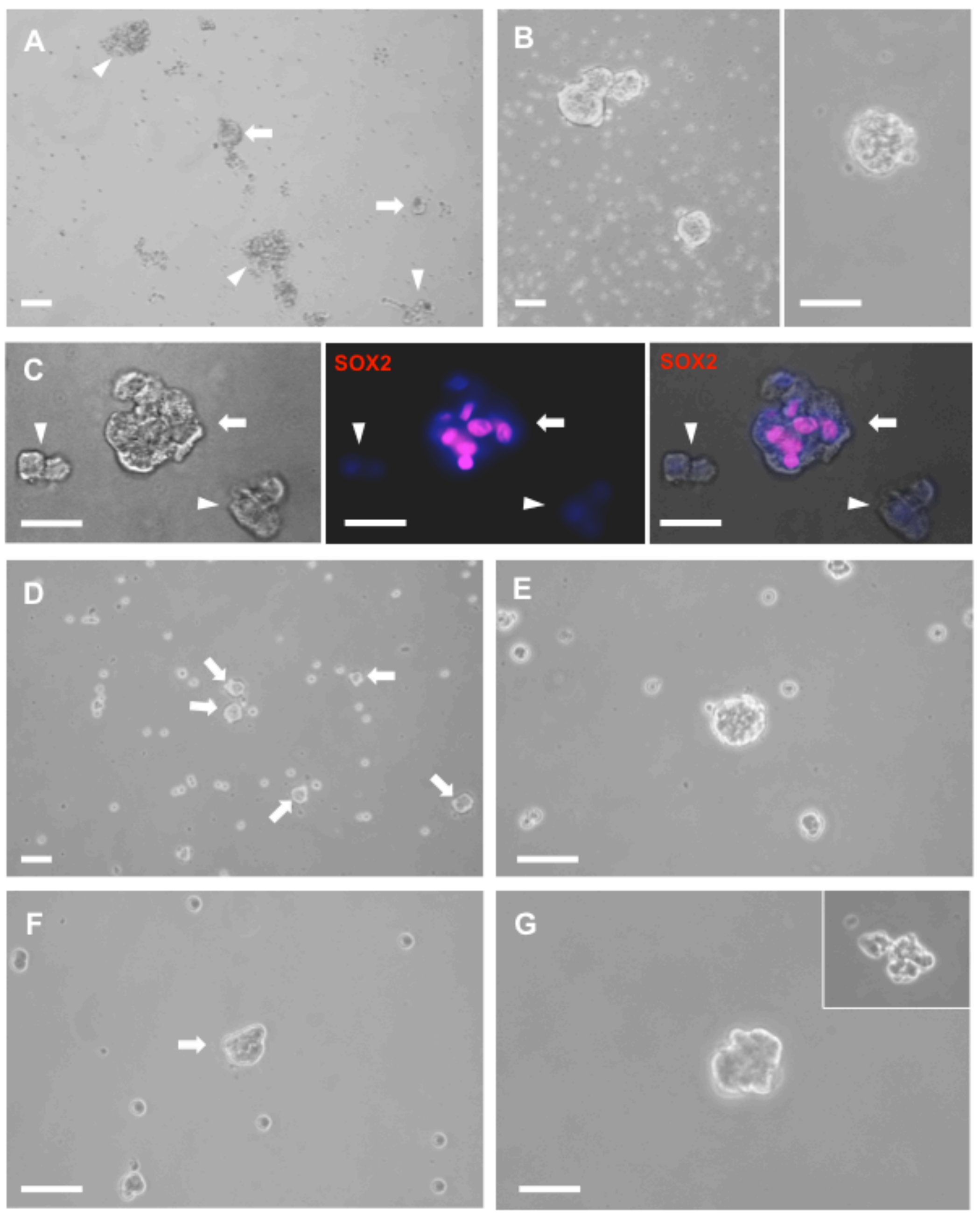
Fig. 3

A

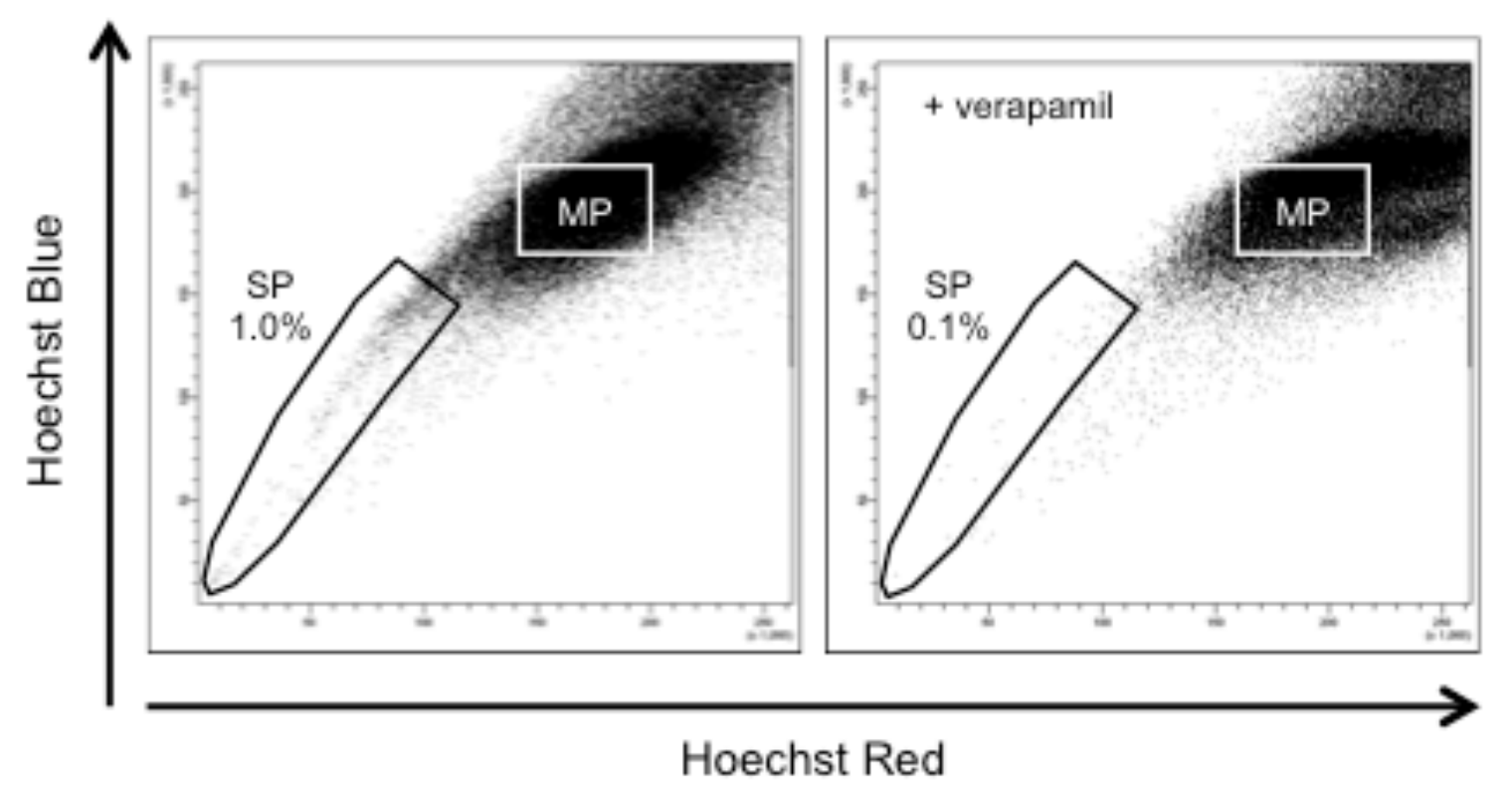

B

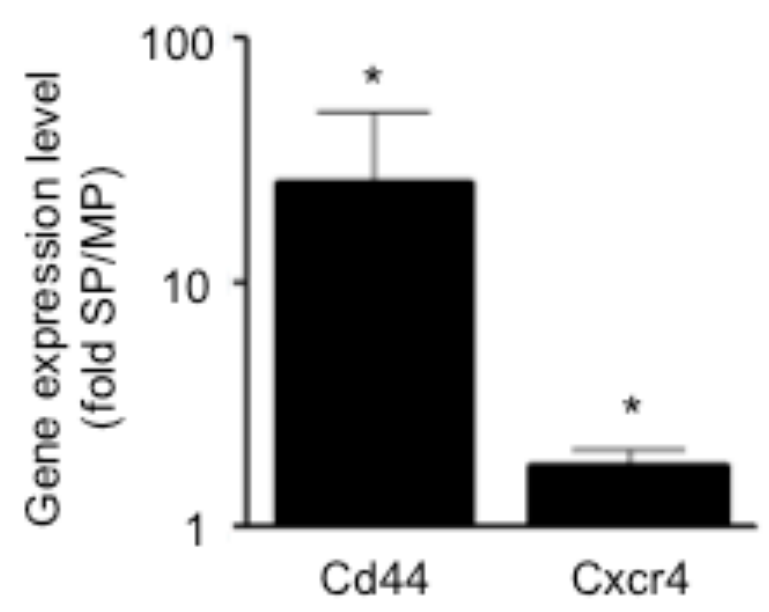

C

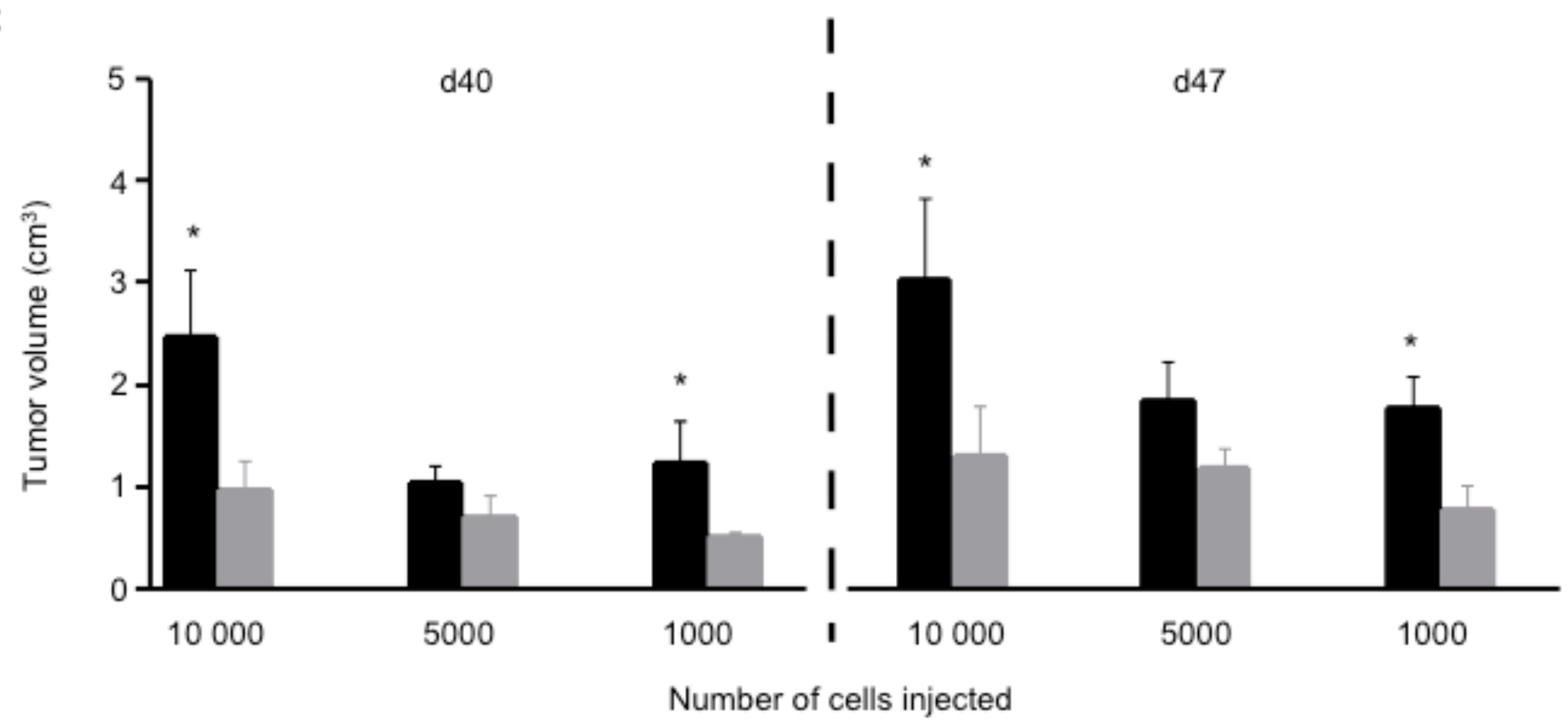


Fig. 4

A

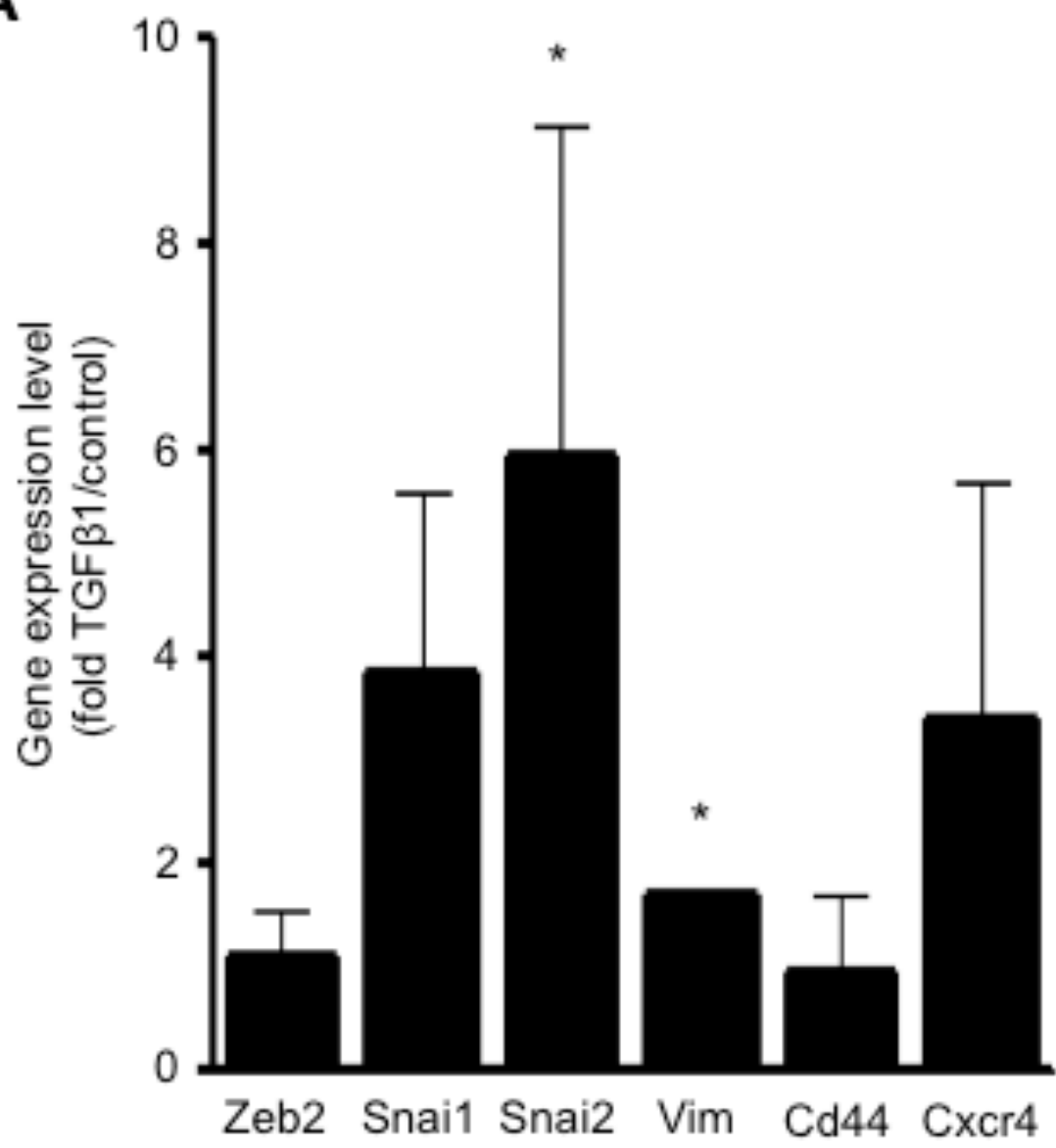

C

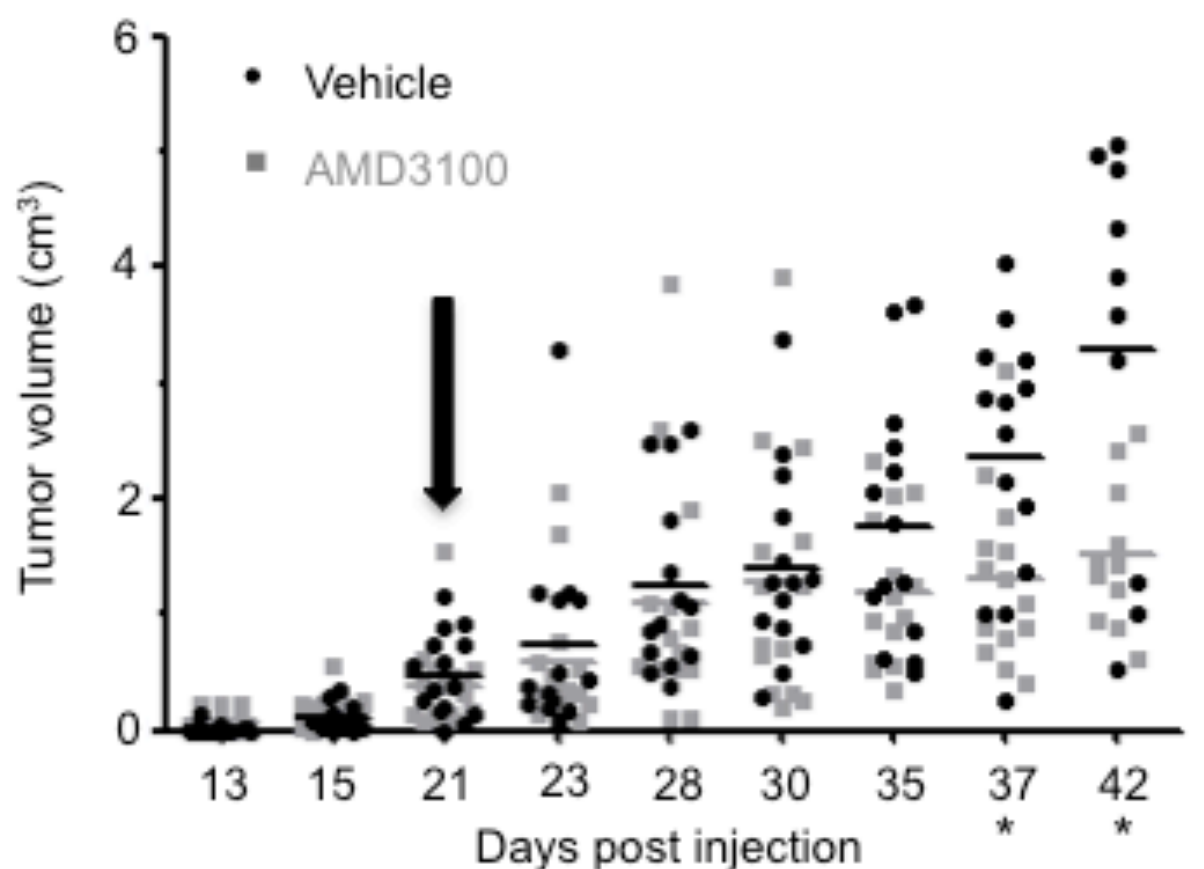

E

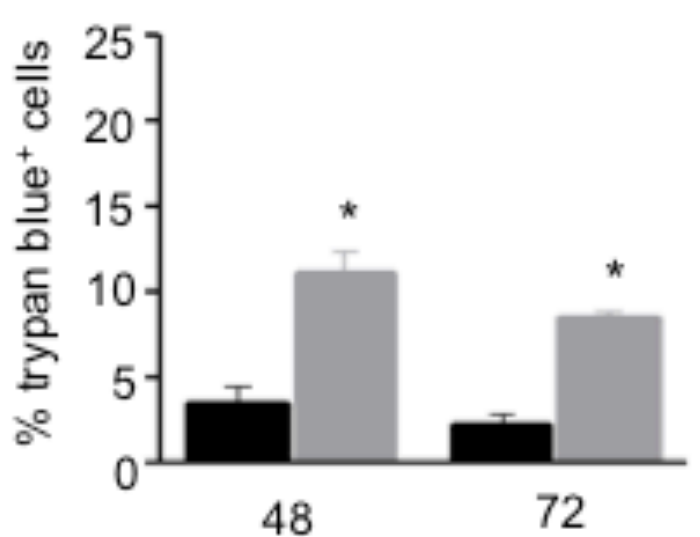

Treatment period (hr)
B
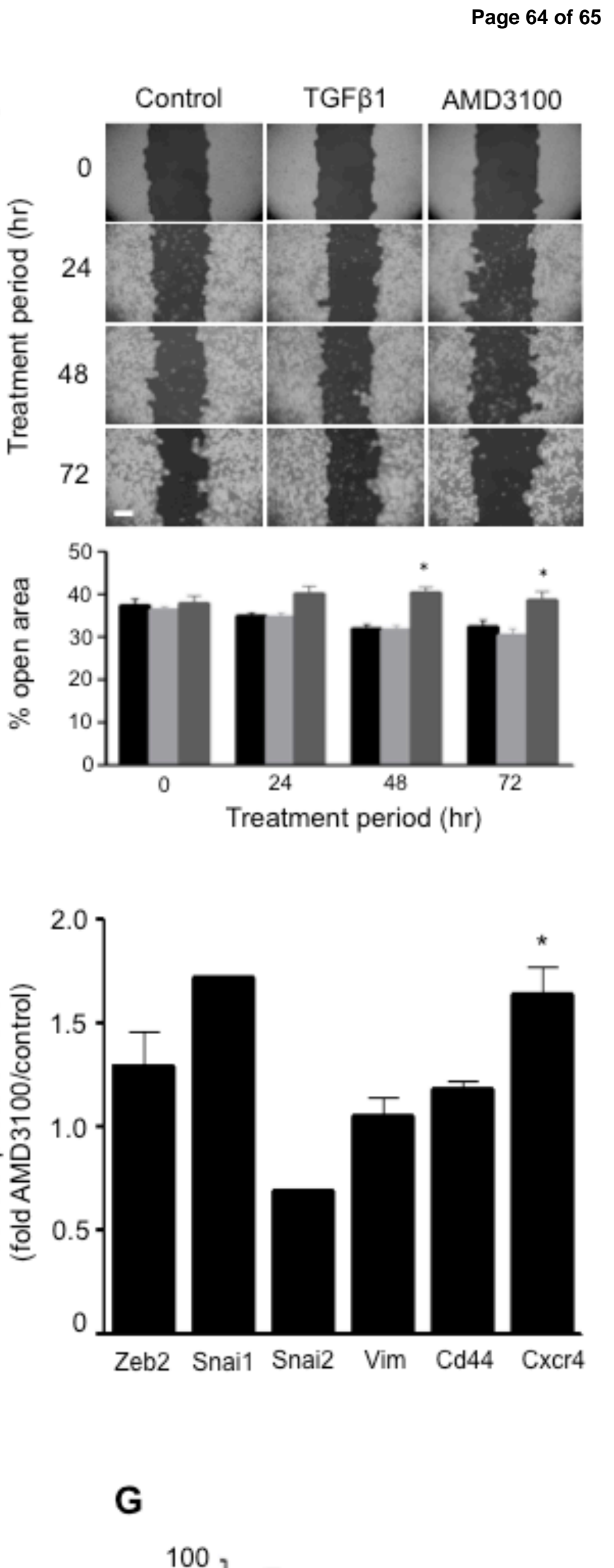

D

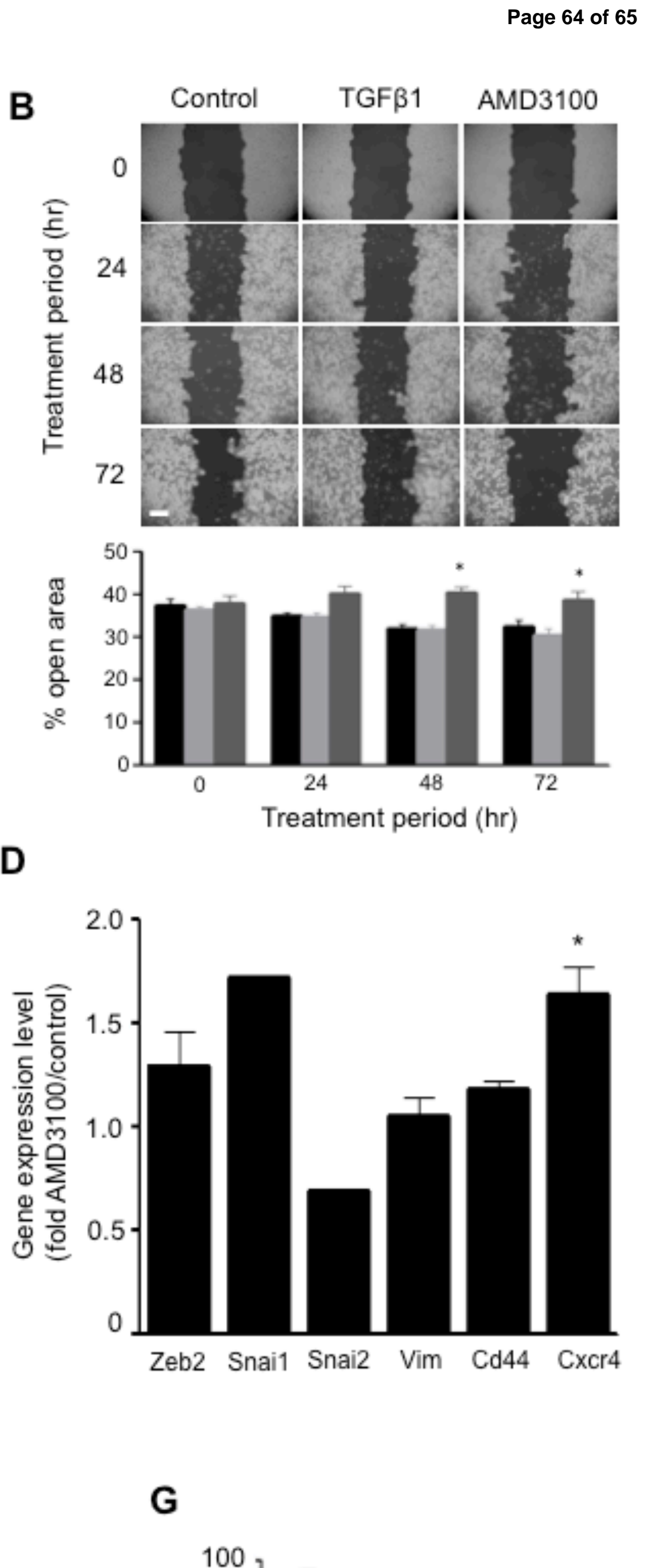

G

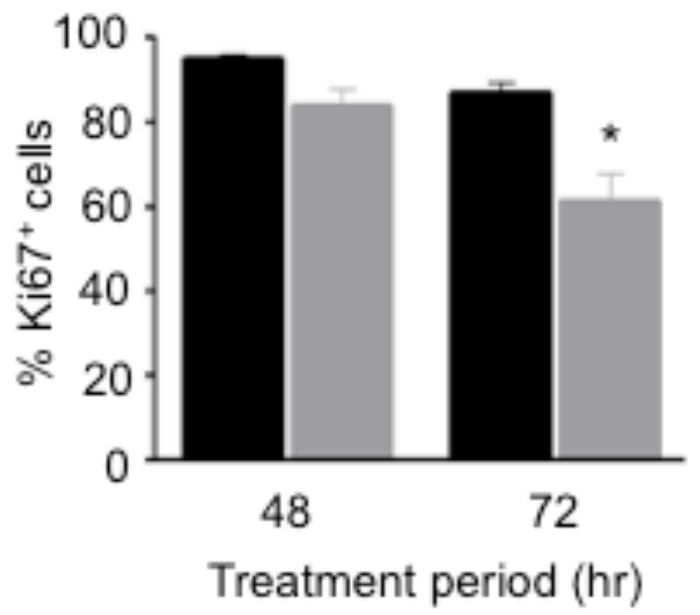


Fig. 5

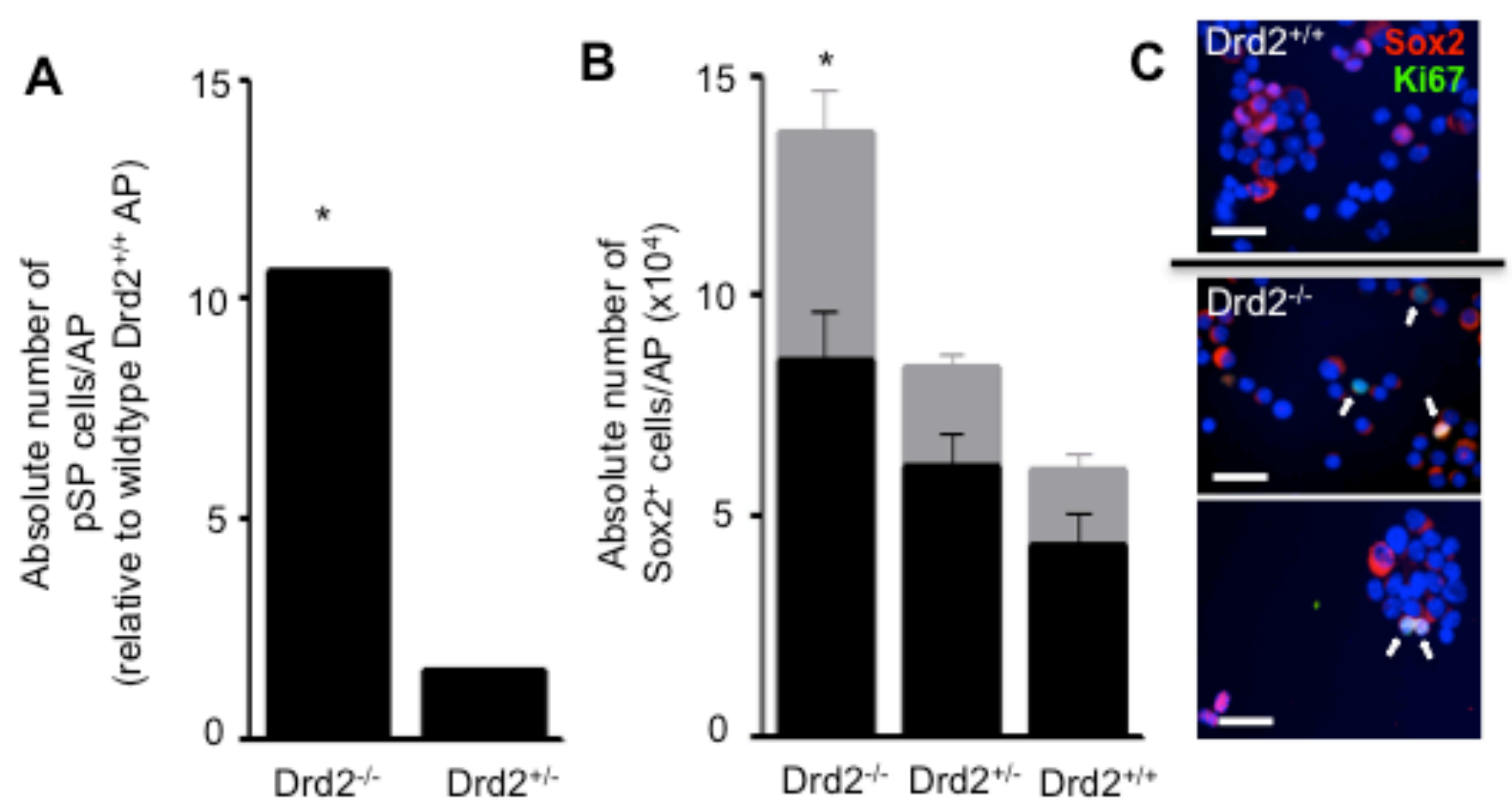

D
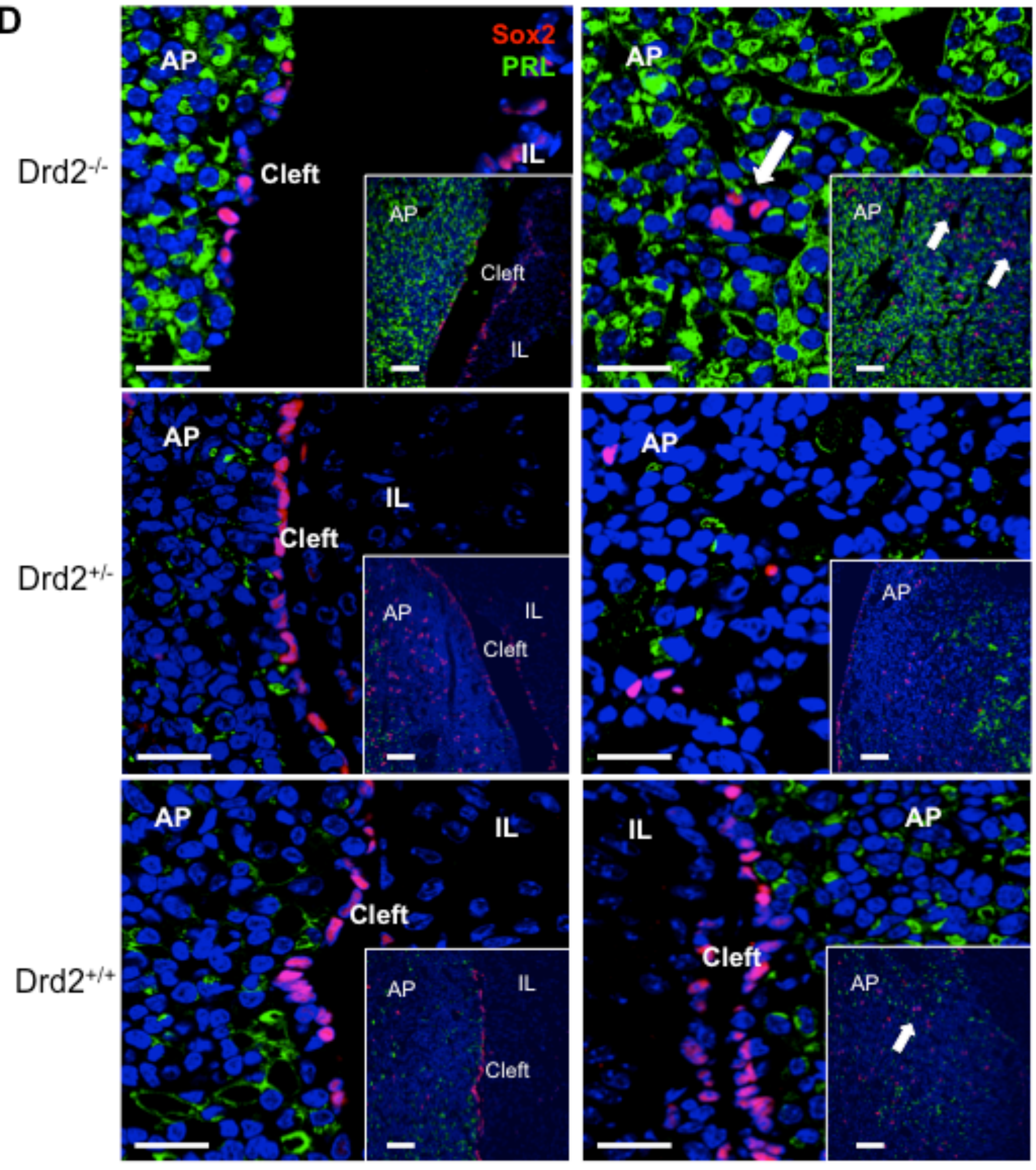